\title{
Mitochondrial membrane potential acts as a retrograde signal to regulate cell cycle progression
}

\author{
Choco Michael Gorospe ${ }^{1}$, Alicia Herrera Curbelo ${ }^{1}$, Gustavo Carvalho ${ }^{1}$, Lisa Marchhart ${ }^{1}$, \\ Katarzyna Niedźwiecka ${ }^{1,2}$ and Paulina H. Wanrooij, ${ }^{1, *}$ \\ ${ }^{1}$ Department of Medical Biochemistry and Biophysics, Umeå University, 90187 Umeå, \\ Sweden; ${ }^{2}$ Institute of Biochemistry and Biophysics, Polish Academy of Sciences, 00090 \\ Warsaw, Poland.
}

*Correspondence: paulina.wanrooij@umu.se

\begin{abstract}
Mitochondria are central to numerous anabolic and catabolic pathways whereby mitochondrial dysfunction has a profound impact on metabolism and can manifest in disease. The consequences of mitochondrial dysfunction can be ameliorated by adaptive responses that rely on mito-cellular crosstalk to communicate mitochondrial distress to the rest of the cell. Such mito-cellular signaling slows cell cycle progression in mitochondrial-DNA deficient $\left(\rho^{0}\right)$ Saccharomyces cerevisiae cells, but the initial trigger and the pathway mediating the response has remained unknown. Here, we show that decreased mitochondrial membrane potential $(\Delta \Psi \mathrm{m})$ acts as the initial signal of mitochondrial stress that delays G1-to-S phase transition in both $\rho^{0}$ and control cells. Accordingly, experimentally increasing $\Delta \Psi \mathrm{m}$ was sufficient to restore timely cell cycle progression in $\rho^{0}$ cells. Neither the RTG retrograde pathway nor central DNA damage checkpoint kinases were involved in mediating this form of mito-cellular communication. The identification of $\Delta \Psi \mathrm{m}$ as a novel regulator of cell cycle progression may have implications for disease states involving mitochondrial dysfunction.
\end{abstract}

Running title: Mt membrane potential controls the cell cycle

Keywords: mitochondria, retrograde signaling, mito-cellular communication, mtDNA inheritance checkpoint 


\section{Introduction}

Mitochondria use the electron transport chain (ETC) complexes to convert energy gained from the oxidation of nutrients into an electrochemical gradient across the inner mitochondrial membrane; this electrochemical gradient is then used to drive ATP synthesis through the process of oxidative phosphorylation (OXPHOS). In addition to producing the majority of the cell's ATP, however, mitochondria carry out a diverse array of vital cellular functions including synthesis of Fe-S clusters, amino acid and nucleotide biosynthesis, the production of reactive oxygen species (ROS) and apoptosis. It follows that mitochondrial function is required for cell survival even in a facultative anaerobe like the budding yeast Saccharomyces cerevisiae that can survive without mitochondrial ATP production. In line with the manifold functions of the organelle, mitochondrial dysfunction is associated with numerous diseases including neurodegenerative disorders, metabolic syndrome, cancer, as well as aging (Nunnari and Suomalainen, 2012; Raimundo, 2014). Rather than manifesting merely as an energy defect, mitochondrial dysfunction can contribute to cellular dysfunction and disease etiology through diverse mechanisms involving e.g. increased levels of ROS that can damage cellular constituents, changes in nuclear epigenetic marks or gene expression patterns, and even instability of the nuclear genome (Leadsham et al., 2013; Nunnari and Suomalainen, 2012; Kopinski et al., 2019; Veatch et al., 2009).

To avoid or ameliorate the dire consequences of mitochondrial dysfunction, a complex communication network mediates signals of mitochondrial status to other parts of the cell including the nucleus, lysosomes, peroxisomes and the endoplasmic reticulum (Nunnari and Suomalainen, 2012; Raimundo, 2014). This mito-cellular signaling can be mediated by signals ranging from key metabolites to misfolded proteins or ROS, and acts to restore cellular homeostasis, facilitate adaptation to the altered mitochondrial status, or eliminate dysfunctional mitochondria via mitophagy (Mottis et al., 2019).

The most thoroughly understood pathway of mito-cellular communication is the RTG (retrograde) pathway in S. cerevisiae that is activated in response to mitochondrial dysfunction such as respiratory chain deficiency or loss of mitochondrial DNA (mtDNA) (Parikh et al., 1987; Liu and Butow, 2006). The RTG pathway relies on the heterodimeric Rtg1-Rtg3 transcription factor to activate the expression of RTG target genes and ensure sufficient synthesis of glutamate - the main source of nitrogen in biosynthetic processes - even in the absence of mitochondrial function (Liu and Butow, 2006). Activation of the RTG response requires the positive regulator Rtg2 that promotes the partial dephosphorylation and consequent nuclear translocation of the 
normally cytosolic Rtg1-Rtg3 complex, thus enabling activation of the RTG response. The initial signal triggering this retrograde pathway has been reported to be the drop in mitochondrial membrane potential $(\Delta \Psi \mathrm{m})$ that accompanies loss of mtDNA and respiratory deficiency (Miceli et al., 2012).

MtDNA encodes key subunits of the ETC complexes as well as the $F_{o}$ component of the ATP synthase, making this small genome essential for cellular respiration and OXPHOS. It follows that cells lacking mtDNA (termed $\rho^{0}$ cells) cannot maintain $\Delta \Psi \mathrm{m}$ by proton pumping; instead, they maintain a limited $\Delta \Psi \mathrm{m}$ by a mechanism involving the hydrolysis of ATP by the "reverse" action of the $F_{1}$ component of the ATP synthase in consort with the electrogenic exchange of $\mathrm{ATP}^{4-}$ for $\mathrm{ADP}^{3-}$ by the adenine nucleotide translocator ANT (Giraud and Velours, 1997; Buchet and Godinot, 1998; Appleby et al., 1999). Certain mutations in subunits of the $\mathrm{F}_{1^{-}}$ ATPase increase the activity of the enzyme, resulting in a higher ANT-driven membrane potential in $\rho^{0}$ cells (Kominsky et al., 2002).

In addition to preventing cellular respiration and decreasing $\Delta \Psi \mathrm{m}$, mtDNA loss promotes nuclear DNA instability and defective cell cycle progression that manifests as an accumulation of cells in G1 phase (Veatch et al., 2009; Zyrina et al., 2015). In an elegant study, Veatch et al. showed these two effects to be separate from each other: while the nuclear DNA instability in mtDNA-depleted cells was driven by defective Fe-S cluster protein assembly, the mechanism(s) underlying the cell cycle defect were not uncovered but were found to be independent of Fe-S metabolism (Veatch et al., 2009). A subsequent study suggested the cell cycle phenotype of $\rho^{0}$ cells - termed the mtDNA inheritance checkpoint - to be dependent on the Rad53 checkpoint kinase that is central in the cell's response to nuclear DNA damage or replication stress (Crider et al., 2012). In canonical checkpoint signaling, Rad53 functions downstream of the Mec1 master kinase that is activated in response to stretches of Replication Protein A-coated single-stranded DNA, a sign of replication stress or DNA damage (Wanrooij et al., 2016; Navadgi Patil and Burgers, 2011). Once active, Mec1 stimulates Rad53 to phosphorylate numerous downstream targets to arrest cell cycle progression and upregulate DNA repair in order to ensure the damage is resolved prior to cell division. A second master kinase of the same phosphoinositide 3-kinase related kinase family as Mec1, Tel1, phosphorylates a partly-overlapping network of targets to guarantee the timely repair of doublestranded DNA breaks (Harrison and Haber, 2006). The involvement of the Mec1 and Tell master kinases in the cell cycle phenotype of $\rho^{0}$ cells has to our knowledge not been addressed. 
Despite the undisputed involvement of mitochondrial dysfunction in human disease, the molecular-level events that link mtDNA loss to the cell cycle machinery, as well as the mitochondria-proximal signal that initiates this form of mito-cellular communication remain uncharacterized. Here, we analyzed the dependence of the $\rho^{0}$ cell cycle defect on canonical checkpoint proteins and on the RTG signaling pathway, and find both to be dispensable for the G1-to-S phase progression delay known as the mtDNA inheritance checkpoint. Remarkably, a combination of genetic and pharmaceutical interventions uncovered decreased mitochondrial membrane potential as a regulator of cell cycle progression in both $\rho^{+}$and $\rho^{0}$ cells, while inhibition of mitochondrial ATP synthesis or altered ROS levels did not account for the cell cycle phenotype of mtDNA-depleted cells. Finally, we show that the cell cycle defect in $\rho^{0}$ cells can be rescued by increasing $\Delta \Psi \mathrm{m}$, confirming that adequate $\Delta \Psi \mathrm{m}$ rather than mitochondrial function per se is required for normal cell cycle progression. These findings identify the mitochondrial membrane potential as a novel regulator of cell cycle progression.

\section{Results}

\section{$P^{0}$ cells exhibit slow growth characterized by G1-to-S phase transition delay}

In order to study the effects of mtDNA loss, an mtDNA-devoid $\left(\rho^{0}\right)$ variant of the mtDNAcontaining $\left(\rho^{+}\right)$wildtype (WT) strain was made by standard treatment with ethidium bromide (Goldring et al., 1970), and confirmed by quantitative real-time PCR. $\mathrm{P}^{0}$ yeast cells are respiratory-deficient and can thus only grow on fermentable carbon sources such as dextrose. In accordance with previous reports, $\rho^{0}$ cells formed characteristic small colonies on dextrosecontaining rich medium, and grew slower than their $\rho^{+}$counterparts, unable to exceed an $\mathrm{OD}_{600}$ of $c a 6$ even after $48 \mathrm{~h}$ in liquid culture (Fig. 1A; Fig. S1A) (Ephrussi, 1949). Furthermore, the percentage of G1 cells in an early-logarithmic unsynchronized culture of $\rho^{0}$ cells was twice as high as in $\rho^{+}$cells grown under identical conditions; this difference remained constant for at least $2 \mathrm{~h}$ during logarithmic growth (Fig. 1B-C; Fig. S1B). To test whether the increased frequency of G1 cells in the unsynchronized $\rho^{0}$ culture was due to a slower G1-to-S transition or a faster progression through other cell cycle stages, we synchronized cells at the G1/S boundary using the $\alpha$-factor pheromone and compared the timing of S phase entry in $\rho^{+}$and $\rho^{0}$ cells. Following release from G1 synchrony, the number of $\rho^{+}$cells in G1 phase started to decrease after $c a 20$ min, signifying entry into $\mathrm{S}$ phase (Fig. 1D-E). However, $\rho^{0}$ cells took significantly longer to transition from G1 to S phase, as the frequency of G1 cells did not begin 
to decrease until over 30 min after release from $\alpha$-factor synchrony. To confirm that the G1-to$S$ transition delay was a true phenotype of the $\rho^{0}$ variant and not an artifact of the $\alpha$-factor treatment or an overall slower transition through the cell cycle, cells were next synchronized in G2 by nocodazole treatment. Interestingly, $\rho^{+}$and $\rho^{0}$ cells released from nocodazole synchrony showed comparable timing of G2 exit and entered the G1 phase around 50 minutes after release (Fig. 1F; Fig. S1C-D). However, while $\rho^{+}$cells continued straight into $\mathrm{S}$ phase (as shown by an accumulation of $\mathrm{S}$ phase cells peaking at $70 \mathrm{~min}), \rho^{0}$ cells accumulated in G1 and displayed delayed entry into S phase (Fig. 1F). Consequenty, the percentage of $\rho^{0}$ cells in S phase did not peak until 90-100 min after release from G2, 20-30 min later than $\rho^{+}$cells (Fig. 1F).

Together, these results demonstrate that $\rho^{0}$ cells exhibit slow growth characterized by a delayed G1-to-S transition, and thus confirm previous observations of an impaired G1 exit upon mtDNA loss that has been termed the mtDNA inheritance checkpoint (Crider et al., 2012; Veatch et al., 2009; Zyrina et al., 2015). However, the factors mediating the mtDNA inheritance checkpoint, as well as the initial signal that triggers the cell cycle defect, have not been uncovered. Given that this checkpoint has been suggested to be dependent on the Rad53 checkpoint kinase (Crider et al., 2012), we first investigated the requirement of central checkpoint factors for the G1-to-S delay in $\rho^{0}$ cells.

\section{The G1-S delay in $\rho^{0}$ cells is not dependent on central checkpoint kinases including Rad53}

The canonical checkpoint responses that are triggered upon nuclear DNA damage or replication defects are driven by the master checkpoint kinases Tell and Mec1, the orthologs of mammalian ATM and ATR, respectively (Beyer and Weinert, 2014). Mec1 has also been reported to be required for efficient G1 arrest upon nutrient deprivation, a response that could be activated in $\rho^{0}$ cells (Weinberger et al., 2007). We therefore tested the contribution of Tel1 and Mec1 to the G1-to-S delay in $\rho^{0}$ cells by assessing the cell cycle profile of the relevant deletion mutants and their $\rho^{0}$ derivatives. Interestingly, the deletion of TEL1 did not prevent the accumulation of $\rho^{0}$ cells in G1 phase, indicating that the G1-to-S delay observed in $\rho^{0}$ cells is independent of the Tell checkpoint kinase (Fig. 2A; Fig. S2A). We next tested the involvement of Mec1. As null mutation of MEC1 is lethal unless accompanied by deletion of the gene encoding the ribonucleotide reductase inhibitor Sml1, the analyses were carried out in a smll $\Delta$ background (Zhao et al., 1998). The cell cycle profiles of the $\operatorname{smll\Delta } \rho^{+}$and $\rho^{0}$ cells were comparable to their WT counterparts (Fig. 2B; Fig. S2A). Similar to TEL1, deletion of MEC1 in $s m l 1 \Delta$ cells did not prevent the increase in G1 cells in the $\rho^{0}$ variant (Fig. 2B; Fig. S2A). 
Furthermore, and in accordance with Fig. 2A, deletion of TEL1 in sml1 $\triangle$ cells did not alter the cell cycle profile of $\rho^{+}$or $\rho^{0}$ cells (Fig. S2B). We conclude that neither the Tel1 nor the Mec1 master checkpoint kinase are required for the delayed G1-to-S transition observed in $\rho^{0}$ cells.

In canonical checkpoint signaling, activated Mecl phosphorylates and activates the downstream Rad53 effector kinase (Sanchez et al., 1996; Hoch et al., 2013). Given that we found the G1-to-S transition delay in $\rho^{0}$ cells to be independent of Mec1, we revisited the suggested dependence of this phenotype on Rad53. Similar to MEC1, RAD53 is an essential gene and its deletion can only be achieved via prior inactivation of the $S M L 1$ gene. The percentage of G1

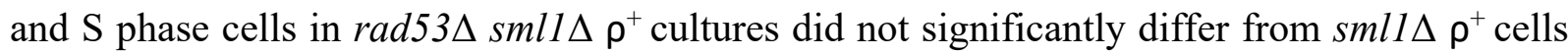
(Fig. 2B; Fig. S2A). Similarly, rad53 $\Delta$ sml1 $\Delta$ cells showed an increased percentage of G1 cells in $\rho^{0}$ compared to $\rho^{+}$cells, although the increase was somewhat more modest than in $\operatorname{smll\Delta }(\mathrm{G} 1$ cells in rad53 $\operatorname{smll\Delta }$ increased from 20 to $31 \%$ after conversion from $\rho^{+}$to $\rho^{0}$, respectively, compared to 17 and $43 \%$ in $s m l 1 \Delta$ ). These findings indicate that $\operatorname{Rad} 53$ is not required for the G1-to-S transition delay observed in $\rho^{0}$ cells under our experimental conditions. We observed comparable results in another independent $\operatorname{rad} 53 \Delta \operatorname{smll} \Delta$ strain as well as in a rad53 $\Delta \operatorname{sml} 1-1$ strain in another W303-derivative background (Fig. S2C). Finally, we used Western blot analysis to directly assay for potential Rad53 activation in $\rho^{0}$ cells. Although the gel migration of Rad53 was clearly retarded in $\rho^{+}$cells treated with the DNA damaging agent 4-NQO, indicating that Rad53 phosphorylation was readily detected in our assay, no phosphorylation of Rad53 was detected in WT $\rho^{0}$ cells (Fig. 2C).

These results therefore indicate that the G1-to-S phase progression delay observed in WT $\rho^{0}$ cells is independent of the Mec1/Rad53 and Tel1 checkpoint signaling pathways.

\section{The RTG-dependent retrograde signaling pathway is not required for the G1-to-S phase delay in $\rho^{0}$ cells}

The RTG pathway is the most thoroughly-understood pathway for mitochondria-tonucleus signaling upon mitochondrial dysfunction. This retrograde pathway is activated upon mtDNA loss, and is thereby a prime candidate for mediating the signaling that leads to the G1to-S transition delay in mtDNA-depleted cells (Liao and Butow, 1993; Kirchman et al., 1999). We first tested the effect of deleting the gene encoding the proximal sensor of the RTG pathway, $R T G 2$. The cell cycle profile of $r \operatorname{tg} 2 \Delta \rho^{+}$and $\rho^{0}$ cells was similar to that of their WT counterparts, and the percentage of G1 cells was considerably higher in $r \operatorname{tg} 2 \Delta \rho^{0}$ than $\operatorname{rtg} 2 \Delta \rho^{+}$cells, indicating that Rtg2 was not required for the G1-to-S delay (Fig. 3 and Fig. S3). Even Rtg3, which contains 
the transcriptional activation domain in the $R \operatorname{tg} 1 / \operatorname{Rtg} 3$ complex (Rothermel et al., 1997), was found to be redundant for the G1-to-S phase delay in $\rho^{0}$ cells (Fig. 3 and Fig. S3). We conclude that although the RTG pathway generally responds to mitochondrial distress and loss of mtDNA, it is not required for the G1-to-S phase progression delay observed in $\rho^{0}$ cells.

\section{Decreased mitochondrial membrane potential delays G1-to-S phase progression}

We next sought to identify the proximal signal that triggers the cell cycle phenotype in mtDNA-deficient cells. Yeast mtDNA encodes subunits of the ETC and the ATP synthase. Consequently, electron transport and OXPHOS are impaired in $\rho^{0}$ cells, resulting in a plethora of outcomes including impaired mitochondrial ATP production, decreased $\Delta \Psi \mathrm{m}$, and increased generation of ROS (Greaves et al., 2012; Houten et al., 2016; Dirick et al., 2014). We reasoned that any of these downstream effects of a malfunctional ETC and OXPHOS were reasonable candidates for the initial signal that triggers the G1-to-S phase delay in $\rho^{0}$ cells, and tested each of them in turn.

We first assessed the effect of pharmacologically inhibiting mitochondrial ATP production using oligomycin, a compound that binds to the Fo subunit of the ATP synthase to prevent the flow of protons back into the mitochondrial matrix (Lee and O'Brien, 2010). Treatment of $\rho^{+}$or $\rho^{0}$ cells with oligomycin did not cause accumulation of cells in G1 phase or decrease the percentage of cells in S phase compared to untreated cells over the observation period of $120 \mathrm{~min}$ following treatment (Fig. 4A, Fig. S4A-B). Therefore, the G1-to-S transition delay in $\rho^{0}$ cells is not triggered by decreased mitochondrial ATP synthesis, a conclusion that is in agreement with previous findings and the fact that we assay for the cell cycle delay during early logarithmic growth on dextrose-containing media when ATP generation primarily occurs by fermentation rather than by mitochondrial respiration (van Dijken et al., 1993; Crider et al., 2012).

We next tested the importance of the $\Delta \Psi \mathrm{m}$ for normal cell cycle progression. To this end, we treated logarithmically growing cells with BAM15, an uncoupler that efficiently dissipates the $\Delta \Psi \mathrm{m}$ without depolarizing the plasma membrane (Kenwood et al., 2014). Interestingly, BAM15 treatment of $\rho^{+}$cells caused a transient accumulation of cells in G1 phase (Fig. 4B, Fig. S4C). The observed accumulation of cells in G1 phase was accompanied by a corresponding decrease in the percentage of cells in S phase. Treatment with another uncoupler, CCCP, caused a similar transient increase in G1 phase cells as BAM15 (Fig. S4D-E). 
To further corroborate the connection between $\Delta \Psi \mathrm{m}$ and G1-to-S progression, we synchronized cells in G1 with $\alpha$-factor and released them into medium containing BAM15. In analogy to the G1-to-S transition delay in $\rho^{0}$ cells, BAM15 treatment delayed the progression of $\alpha$-factor-synchronized $\rho^{+}$cells from G1 into S phase: while the percentage of G1 cells began to decline 20 min after release of $\rho^{+}$cells into normal medium, indicating transition from G1 into $\mathrm{S}$ phase, $\rho^{+}$cells released into BAM15-containing medium did not show signs of G1 exit until 70 min after release (Fig. 4C-D). BAM15-treatment also delayed the G1-to-S transition in $\rho^{+}$ cells released from G2 synchrony: while the presence of BAM15 did not appreciably affect the transition from G2 to G1 phase, $\rho^{+}$cells released from G2 into BAM15-containing medium showed an increased percentage of G1 cells and delayed S phase entry, consistent with a G1-toS transition delay (Fig. S4F-I).

The results of Figure 4 demonstrate that while the inhibition of mitochondrial ATP synthesis has no apparent impact on cell cycle progression, a $\Delta \Psi \mathrm{m}$ collapse induced by uncoupler treatment causes cells to accumulate in G1 phase by triggering a G1-to-S phase transition delay similar to the one observed in $\rho^{0}$ cells. These findings implicate $\Delta \Psi \mathrm{m}$ in modulating cell cycle progression $\rho^{+}$cells.

\section{The cell cycle defect in $\rho^{0}$ cells is exacerbated by a further reduction of membrane potential}

In contrast to uncoupler-treated cells where the $\Delta \Psi \mathrm{m}$ is largely dissipated, $\rho^{0}$ cells have the ability to maintain a membrane potential that, although lower than in $\rho^{+}$cells, is still sufficient to support various $\Delta \Psi \mathrm{m}$-dependent processes like the import of nuclear-encoded mitochondrial proteins (Miceli et al., 2012; Appleby et al., 1999). Next, we examined whether the decreased $\Delta \Psi \mathrm{m}$ could underlie the cell cycle phenotype of $\rho^{0}$ cells and act as the initial signal to trigger the G1-to-S transition delay. We measured the $\Delta \Psi \mathrm{m}$ of WT $\rho^{+}$and $\rho^{0}$ cells using the fluorescent cationic dye tetramethylrhodamine methyl ester perchlorate (TMRE), and corrected the signal for potential changes in mitochondrial mass as detected by nonylacridine orange (NAO), a green-fluorescent dye that localizes to the mitochondria in a $\Delta \Psi$ m-independent manner (Doherty and Perl, 2017). Uncoupler-treated samples analyzed in parallel provided a measure of the background fluorescence. As expected, the $\Delta \Psi \mathrm{m}$ of WT $\rho^{0}$ cells was significantly lower than that in WT $\rho^{+}$cells, but clearly higher than the baseline value of uncoupler-treated cells (Fig. 5A, Fig. S6A-B).

In additional support of a role for $\Delta \Psi \mathrm{m}$ in regulating cell cycle progression, the accumulation of $\rho^{0}$ cells in $\mathrm{G} 1$ phase was further exacerbated when $\Delta \Psi \mathrm{m}$ was fully dissipated 
by BAM15 or CCCP treatment (Fig. 5B, Fig. S5A-C). Furthermore, the effect of BAM15 was more sustained in $\rho^{0}$ than in $\rho^{+}$cells and was evident even $2 \mathrm{~h}$ after addition of the compound (compare Fig. 5B and Fig. 4B). Expectedly, time course experiments following release from $\alpha-$ factor or nocodazole-induced synchrony revealed a more severe G1-to-S phase progression delay in $\rho^{0}$ cells in the presence of BAM15 (G1 exit starting $40 \mathrm{~min}$ and $80 \mathrm{~min}$ after release from $\alpha$-factor synchrony into medium lacking or containing BAM15, respectively) (Fig. 5C-D, Fig. S5D-F). These observations establish a quantitative correlation between $\Delta \Psi \mathrm{m}$ and cell cycle progression, where the extent of the G1-to-S delay is governed by the severity of $\Delta \Psi \mathrm{m}$ loss.

\section{ATP1-111 rescues the cell cycle phenotype of $\rho^{0}$ cells}

$\mathrm{P}^{0}$ cells differ significantly from $\mathrm{\rho}^{+}$cells in terms of metabolism given that respiratorydeficient $\rho^{0}$ cells must compensate for the loss of a subset of the citric acid cycle reactions, the products of which are central to many anabolic pathways (Epstein et al., 2001). If the G1-to-S phase progression delay is indeed driven by decreased $\Delta \Psi \mathrm{m}$ and not by other functional or metabolic differences between $\rho^{+}$and $\rho^{0}$ cells, we hypothesized that it should be rescued by increasing $\Delta \Psi \mathrm{m}$ in $\rho^{0}$ cells. In the absence of ETC activity, mtDNA-deficient cells maintain $\Delta \Psi \mathrm{m}$ by an alternative mechanism that involves the hydrolysis of glycolytically-produced ATP by the "reverse" action of the F1 subunit of the mitochondrial ATP synthase and the electrogenic exchange of $\mathrm{ATP}^{4-}$ for $\mathrm{ADP}^{3-}$ over the inner mitochondrial membrane (Appleby et al., 1999; Giraud and Velours, 1997). The ATP1-111 mutation in the Atp1 subunit of the mitochondrial F1-ATPase results in a hyperactive enzyme that generates a higher $\Delta \Psi \mathrm{m}$ in $\rho^{0}$ cells than the one maintained in WT $\rho^{0}$ cells (Francis et al., 2007; Veatch et al., 2009; Miceli et al., 2012). Accordingly, analysis of ATP $1-111 \rho^{0}$ cells revealed a $\triangle \Psi \mathrm{m}$ comparable to WT $\rho^{+}$cells, confirming the ATP1-111 $\rho^{0}$ strain as a suitable model to test our hypothesis in (Fig. 6A, Fig. S6A-B).

We first analyzed the cell cycle profile of unsynchronized WT and ATP1-111 $\rho^{+}$and $\rho^{0}$ cells. As expected based on the relatively high $\triangle \Psi \mathrm{m}$ in ATP1-111 $\rho^{+}$cells, the strain showed a cell cycle profile that was indistinguishable from WT $\rho^{+}$cells (Fig. 6B-C). Remarkably, analysis of ATP1-111 $\rho^{0}$ cells revealed that the ATP1-111 mutation was able to rescue the cell cycle phenotype of the WT $\rho^{0}$ cell: while WT $\rho^{0}$ cultures contained $32 \%$ of G1 phase cells, in ATP1$111 \rho^{0}$ cultures the percentage of G1 cells was only $18 \%$ and thus comparable to the value in ATP1-111 $\rho^{+}$cells (14\%). Moreover, the colony size of ATP1-111 $\rho^{0}$ did not differ significantly from ATP1-111 $\rho^{+}$cells (Fig. 6D, Fig. S6C), and their growth rate was partially restored relative 
to WT $\rho^{0}$ cells (Fig. S6D) as previously reported by others (Francis et al., 2007; Veatch et al., 2009).

The earlier experiments carried out on WT cells revealed a more sustained effect of BAM15 on the cell cycle profile of $\rho^{0}$ than $\rho^{+}$cells (Fig. 4B and Fig. 5B). We attributed this to the slower recovery of $\Delta \Psi \mathrm{m}$ in $\rho^{0}$ cells that lack a functional ETC. To explore this aspect further, we monitored cell cycle progression in $\rho^{+}$cells lacking Cox4, a nuclear-encoded subunit of complex IV. Unperturbed $\operatorname{cox} 4 \Delta \rho^{+}$cells were able to maintain a $\Delta \Psi \mathrm{m}$ that did not significantly differ from that of WT $\rho^{+}$cells (Fig. 6A, Fig. S6A-B). Accordingly, the deletion of the COX4 gene did not have any obvious effect on the cell cycle profile of unsynchronized $\rho^{+}$cells (Fig. 6B). However, cox $4 \Delta \rho^{+}$cells exhibited a stronger and more sustained cell cycle response to BAM15 than WT or ATP1-111 $\rho^{+}$cells, indicating that a functional ETC aids in timely recovery from uncoupling (Fig. 6E, Fig. S6E). In line with this notion, all three $\rho^{0}$ strains, including the ATP1-111 $\rho^{0}$ with the restored $\triangle \Psi \mathrm{m}$, failed to recover from the BAM15-induced accumulation of G1 cells within the 120 min follow-up period, although the percentage of G1 cells was lower in ATP1-111 $\rho^{0}$ than in WT or cox $4 \Delta \rho^{0}$ cells (Fig. 6F, Fig. S6E). As expected based on their comparable $\Delta \Psi \mathrm{m}$ values, the cell cycle profile of $\operatorname{cox} 4 \Delta \rho^{0}$ cells was similar to WT $\rho^{0}$ cells (Fig. 6A; B-C; F).

Based on the findings in Figure 6, we conclude that the delayed G1-to-S phase progression in $\rho^{0}$ cells can be attributed to a decreased $\Delta \Psi \mathrm{m}$. Moreover, the cell cycle defect and the consequent petite phenotype and slow growth of $\rho^{0}$ cells can be rescued by increasing $\Delta \Psi \mathrm{m}$ through the ATP1-111 mutation, implicating membrane potential — rather than other metabolic adaptations in $\rho^{0}$ cells - as the main determinant of the cell cycle delay. Accordingly, recovery from transient uncoupler-induced cell cycle delay is expedited by a functional ETC.

\section{Altered ROS is not the signal for the G1-to-S phase progression delay in $\rho^{0}$ cells}

Mitochondria are a major source of reactive oxygen species, and mitochondrial dysfunction is often associated with increased levels of intracellular ROS (Leadsham et al., 2013). Furthermore, ROS are documented to influence cell proliferation (Nunnari and Suomalainen, 2012). Therefore, we wanted to determine whether ROS levels play a role in the $\rho^{0}$ G1-to-S phase progression delay. Rather than increasing the percentage of cells in G1 however, elevated ROS following treatment with $\mathrm{H}_{2} \mathrm{O}_{2}$ primarily caused accumulation of WT $\rho^{+}$cells in early S phase, as previously reported by others (Fig. 7A-B; Fig. S7A) (Leroy et al., 
2001). In contrast, decreasing ROS by treatment of WT $\rho^{+}$cells with the antioxidants Nacetylcysteine (NAC) or reduced glutathione (GSH) caused a transient accumulation of cells in G1 phase along with a decrease in the percentage of cells in S phase (Fig. 7C upper panel; Fig. S7B). A similar but more sustained effect of treatment with either NAC or GSH was observed in WT $\rho^{0}$ cells (Fig. 7C lower panel; Fig. S7B). On their own, these data would suggest that neutralizing ROS by antioxidant treatment inhibits G1-to-S transition. However, measurement of $\Delta \Psi \mathrm{m}$ in antioxidant-treated $\rho^{+}$cells revealed considerable effects of the antioxidants on $\Delta \Psi \mathrm{m}$, with a decrease of comparable extent to that of uncoupler treatment (Fig. 7D; Fig. S7C). Similar effects of NAC on $\triangle \Psi m$ have been reported in mammalian cells (Jiao et al., 2016; Al-Nahdi et al., 2018). The impact of antioxidant treatment on $S$. cerevisiae cell cycle progression observed in Fig. $7 \mathrm{C}$ may therefore be indirect and attributable to decreased $\Delta \Psi \mathrm{m}$ rather than lower ROS levels per se.

To further explore the relationship between ROS, $\Delta \Psi \mathrm{m}$ and cell cycle progression, we measured the levels of oxidative stress in our strains of interest using the fluorescent probe $\mathrm{H}_{2}$ DCFDA that reacts with several forms of ROS including $\mathrm{H}_{2} \mathrm{O}_{2}$, hydroxyl and peroxyl radicals (Jakubowski and Bartosz, 2000). As expected (Leadsham et al., 2013), the percentage of cells with an $\mathrm{H}_{2}$ DCFDA signal above baseline levels ("high-ROS cells") was two-fold higher in WT $\rho^{0}$ cells than in WT $\rho^{+}$cells (Fig. 7E, Fig. S7D). Even ATP $1-111 \rho^{0}$ cells exhibited a higher percentage of high-ROS cells than the corresponding $\rho^{+}$strain. Interestingly, while ATP1-111 $\rho^{+}$cells showed a comparable percentage of cells with high ROS as WT (11-12\%), the percentage of high-ROS cells in ATP1-111 $\rho^{0}$ was as high as $92 \%$ and thus $c a$-fold higher than in WT or ATP1-111 $\rho^{+}$cells. Therefore, the rescued cell cycle phenotype in ATP1-111 $\rho^{0}$ cells cannot be attributed to decreased ROS. In line with a lack of correlation between ROS and the cell cycle delay in $\rho^{0}$ cells, in the cox $4 \Delta$ pair of strains, mtDNA-devoid cells had a lower rather than a higher percentage of high-ROS cells when compared to the corresponding $\rho^{+}$cells.

Taken together, these data indicate that although neutralizing intracellular ROS by antioxidant treatment inhibits G1-to-S transition, this effect is likely indirect and mediated by diminished $\Delta \Psi \mathrm{m}$. In support of this interpretation, ROS levels did not correlate with timely cell cycle progression in the yeast strains analyzed. Rather, the collective findings of this study uncover $\Delta \Psi \mathrm{m}$ as a novel modulator of cell cycle progression in eukaryotic cells. 


\section{Discussion}

The complexes of the ETC and ATP synthase are encoded on both cellular genomes, making retrograde communication from the mitochondria to the nucleus a prerequisite for mitochondrial biogenesis and the correct assembly of these critical complexes. Mito-cellular signaling is also required to trigger any compensatory responses that allow the cell to adjust to mitochondrial dysfunction. Therefore, inter-organellar communication initiated in the mitochondria is crucial under both physiological and pathological conditions.

A number of studies have implicated signals of mitochondrial status in the control of cell cycle progression. Mitochondrial dysfunction brought about by ETC mutations was shown to delay G1-to-S transition in Drosophila melanogaster imaginal disc cells (Mandal et al., 2005; Owusu-Ansah et al., 2008). Interestingly, these studies found different mitochondrial cues to be responsible for triggering the G1/S cell cycle checkpoint depending on the underlying ETC subunit mutation: while a complex IV mutation that decreased ATP levels signaled through AMPK and p53 to prevent S phase entry, a complex I mutation induced high ROS and signaled through the Foxo/p27 pathway. These findings highlight the fact that the signals and pathways that modulate the cell cycle in response to mitochondrial dysfunction can vary even within a single type of cell.

In $S$. cerevisiae, the identity of the mitochondrial signal that triggers the accumulation of respiratory-deficient $\rho^{0}$ cells in G1, a response known as the mtDNA inheritance checkpoint, has remained unknown. In the current study, we rule out the two cues of mitochondrial dysfunction identified in Drosophila - loss of mitochondrial ATP production and high ROS — as triggers of the yeast cell cycle delay. Instead, we show that the G1-to-S transition delay observed in $\rho^{0}$ cells is caused by decreased $\Delta \Psi \mathrm{m}$. Accordingly, the cell cycle phenotype of $\rho^{0}$ cells could be recovered by increasing $\Delta \Psi \mathrm{m}$, indicating that low $\Delta \Psi \mathrm{m}$ rather than respiratory deficiency per $s e$ restricts cell cycle progression in $\rho^{0}$ cells (Fig. 5-6). Dissipation of $\Delta \Psi \mathrm{m}$ in $\rho^{+}$cells induced a similar but transient G1-to-S delay (Fig. 4). These results therefore establish mitochondrial membrane potential as a general modulator of cell cycle progression in S. cerevisiae cells.

In mammalian cells, the $\Delta \Psi \mathrm{m}$ has been reported to fluctuate over the course of the cell cycle, with the highest $\Delta \Psi \mathrm{m}$, mitochondrial $\mathrm{O}_{2}$ consumption and ATP synthesis measured just prior to the G1-to-S transition (Schieke et al., 2008; Mitra et al., 2009). Furthermore, Mitra et al. elegantly demonstrated that the boost in $\Delta \Psi \mathrm{m}$ in late-G1 cells was required for $\mathrm{S}$ phase entry (Mitra et al., 2009). The $\Delta \Psi \mathrm{m}$ therefore appears to regulate cell cycle progression even in higher eukaryotes. In addition, the mitochondrial membrane potential is known to govern e.g. 
mitochondrial dynamics and quality control through mitophagy (Meeusen and Nunnari, 2005; Jin et al., 2010), highlighting its role as a central readout of mitochondrial status.

In several models of mitochondrial dysfunction, the G1-to-S progression defect is dependent on the p53 checkpoint protein (Mitra et al., 2009; Mandal et al., 2005). Given that baker's yeast lacks a p53 homolog, we explored the dependence of the $\rho^{0}$ cell cycle phenotype on the upstream central checkpoint kinases Tel1, Mec1 and Rad53. Along with the RTG retrograde signaling pathway that is activated upon diminished $\Delta \Psi \mathrm{m}$ (Miceli et al., 2012), these checkpoint proteins were found to be redundant for this phenomenon, ruling out both the RTG and the canonical checkpoint pathways as mediators of the $\rho^{0}$ cell cycle delay (Fig. 2-3). The identity of the signaling pathway(s) that connect loss of $\Delta \Psi \mathrm{m}$ to the cell cycle machinery therefore remains unclear. Because decreased $\Delta \Psi \mathrm{m}$ can impair transport across the mitochondrial inner membrane, we speculate that the signaling mechanism may involve alterations in e.g. $\mathrm{Ca}^{2+}$ balance and/or protein import. Another interesting question is whether other energy metabolic readouts such as ROS or the levels of key metabolites can modulate the $\Delta \Psi$ m-dependent effects on the cell cycle. These and many related aspects of the mito-cellular communication that regulates the cell cycle progression of $\rho^{0}$ cells should be addressed in future work.

Mitochondrial dysfunction underlies a diverse group of diseases that is caused by defects in mitochondrially-localized proteins encoded on either the nuclear or the mitochondrial genome. The common feature of mitochondrial diseases is defective function of the respiratory chain and/or ATP synthase that leads to insufficient mitochondrial ATP synthesis. In most cases, mitochondrial disorders also involve decreased $\Delta \Psi \mathrm{m}$ (Chung et al., 2021b). However, not all symptoms of mitochondrial disease can be directly attributed to the shortage of ATP, as some stem from (mal)adaptive responses to the mitochondrial dysfunction. For example, dysregulated immune signaling triggered by mtDNA instability was shown to aggravate the metabolic dysfunction in a mouse model with an increased mtDNA mutation load (Lei et al., 2021). Similarly, patient fibroblasts carrying the common m.3242 A $>\mathrm{G}$ mtDNA point mutation exhibited constitutive activation of the PI3K-Akt-mTORC1 signaling axis, the inhibition of which partly improved mitochondrial function (Chung et al., 2021a). These examples illustrate the importance of understanding the various forms of mito-cellular crosstalk and the possible therapeutic potential of inhibiting signaling that in some cases may be more detrimental than beneficial. It remains to be seen whether inhibition of normal cell cycle progression in response to decreased $\Delta \Psi \mathrm{m}$ contributes to any of the symptoms of mitochondrial disease. 


\section{Materials and Methods}

\section{Yeast strains and growth conditions}

Unless otherwise indicated, all Saccharomyces cerevisiae strains used in this study are congenic to W4069-4c which is in a W303 background (Chabes et al., 2003), and are listed in Table 1. To ensure fitness before each experiment, all strains were streaked out from glycerol stocks onto YPDA solid medium (1\% yeast extract, $2 \%$ peptone, $50 \mathrm{mg} / \mathrm{L}$ adenine, $2 \%$ glucose, and $2 \%$ agar). Unless otherwise indicated, yeast cells were grown in YPDA at $30^{\circ} \mathrm{C}$ with shaking at $180 \mathrm{rpm}$.

$\mathrm{P}^{0}$ strains lacking mtDNA were generated by growth in YPDA medium supplemented with $25 \mu \mathrm{M}$ ethidium bromide for 4-15 days depending on the strain (Goldring et al., 1970). Loss of mtDNA was confirmed by lack of growth on YPGA medium (1\% yeast extract, $2 \%$ peptone, $50 \mathrm{mg} / \mathrm{L}$ adenine and 3\% glycerol) in combination with the absence of amplification of a region of the mitochondrially-encoded $C O X 1$ gene by quantitative real-time PCR in samples where a region of the nuclear-encoded $A C T 1$ gene amplified. Real-time PCR reactions contained $0.2 \mu \mathrm{M}$ forward and reverse primers targeting COX1 or ACT1 (Table 2) and $10 \mu 12 \mathrm{x}$ SyGreen Mix (PCRBiosystems, USA), and were run on a LightCycler 96 instrument (Roche, Switzerland) using the following program: $95^{\circ} \mathrm{C} 180 \mathrm{sec}, 45$ cycles of $\left(95^{\circ} \mathrm{C} 10 \mathrm{sec}, 56^{\circ} \mathrm{C} 10 \mathrm{sec}, 72^{\circ} \mathrm{C} 1 \mathrm{sec}\right.$ with signal acquisition), melting curve $\left(95^{\circ} \mathrm{C} 5 \mathrm{sec}, 65^{\circ} \mathrm{C} 60 \mathrm{sec}\right.$, heating to $97^{\circ} \mathrm{C}$ at $1 \mathrm{sec}$ with continuous signal acquisition).

The strain bearing the ATP1-111 mutation was generated by introduction of the ATP1 variant carrying a $\mathrm{T}>\mathrm{G}$ substitution at position 331 from a $\mathrm{pRS} 316$ integration vector as previously described (Francis et al., 2007; Miceli et al., 2012). Briefly, the ATP1-111 insert in pRS306 was excised with BamHI and XbaI and re-cloned into the pRS316 integration vector. Yeast cells were transformed using a standard lithium acetate procedure (Gietz et al., 1995), and the presence of the mutation in cells that grew in medium supplemented with 5-FOA was confirmed by sequencing.

Deletion strains were constructed by replacing the entire open reading frame (ORF) with the kanMX4 or natMX cassette (Bähler et al., 1998). Gene deletion was confirmed by growth in geneticin or nurseothricin, respectively, as well as by PCR using both a primer pair that flanks the ORF and a pair internal to it. PW36-3B, PW38-5B and PW39-3B were derived from 
backcrosses of TOY782 (Tsaponina et al., 2011), PY220 and PY304 (kind gifts of Dr. P. Burgers), respectively, to AC402/AC403.

\section{Colony size and growth curves}

Yeast strains grown in YPDA liquid medium for at least $24 \mathrm{~h}$ were counted using a Neubauer Improved Hemocytometer and adjusted to 100 cells per $100 \mu \mathrm{dH}_{2} \mathrm{O} .100 \mu \mathrm{l}$ of the cell suspension was spread on a single partitioned YPDA plate and incubated at $30^{\circ} \mathrm{C}$ for $48 \mathrm{~h}$ prior to imaging on a ChemiDoc imaging system (Bio-Rad). The area of all colonies, except for ones with another colony attached to them, was analyzed using ImageJ and individual values were normalized to the average of all WT $\rho^{+}$cell colonies.

For growth curves, yeast strains cultured overnight in YPDA liquid media were reinoculated in fresh media with starting $\mathrm{OD}_{600}=0.1$ or 0.03 . $\mathrm{OD}_{600}$ readings were recorded every $3 \mathrm{~h}$ by spectrophotometry.

\section{Cell cycle analysis by flow cytometry}

Cells grown overnight in YPDA were diluted to a fresh medium to a starting $\mathrm{OD}_{600}$ of 0.1. Cells were harvested at $\mathrm{OD}_{600} 0.35-0.5$, fixed with cold $70 \%$ ethanol and incubated at $4{ }^{\circ} \mathrm{C}$ overnight. The fixed cells were washed with distilled water once, resuspended in $50 \mathrm{mM}$ Tris$\mathrm{HCl}$ pH 7.5 with $15 \mathrm{mM} \mathrm{NaCl}$, and treated with $2 \mathrm{mg} / \mathrm{ml} \mathrm{RNase} \mathrm{A}$ at $37^{\circ} \mathrm{C}$ overnight. The next day, samples were treated with $1.8 \mathrm{mg} / \mathrm{ml}$ proteinase $\mathrm{K}$ at $50{ }^{\circ} \mathrm{C}$ for $1 \mathrm{~h}$, spun down and resuspended in $50 \mathrm{mM}$ Tris $\mathrm{pH} 7.5$. An aliquot was added to $50 \mathrm{mM}$ Tris $\mathrm{pH} 7.5$ containing a 1:10,000 dilution of SYBR green nucleic acid stain (Invitrogen, USA). The cell suspension was sonicated for $10 \mathrm{sec}$ with an amplitude of $20 \%$ before analysis (QSonica Q500, USA). DNA content was detected in the FL1 channel using the Cytomics FC500 (Beckman Coultier, USA). Data analysis and quantification of cells in G1, S and G2 phases was performed using FCS Express 7 Flow (De Novo Software). The y-axis scale of the cell cycle histograms was adjusted to fit the highest cell count.

For time-course analysis of unsynchronized cells, $30 \mathrm{ml}$ culture (with starting $\mathrm{OD}_{600}$ of 0.1) was grown to an $\mathrm{OD}_{600}$ of $0.4-0.6$, split into two portions and the specified drug added to one portion while the other served as a control. Cell aliquots were harvested and immediately fixed every 15 minutes for 2 hours. Time 0 indicates addition of the drug.

For analysis of synchronized cells, cultures were synchronized in G1 by the addition of $5 \mu \mathrm{g} / \mathrm{ml}$ alpha-factor pheromone every hour for $2 \mathrm{~h}$. For G2 synchronization, cells were treated with $10-25 \mu \mathrm{g} / \mathrm{ml}$ nocodazole for 2 hours. Cells were washed twice with one volume of ice-cold 
distilled water and released from synchrony by resuspension in fresh medium. Cells were harvested and immediately fixed every $10 \mathrm{~min}$ for $90-120 \mathrm{~min}$ following release.

\section{Mitochondrial membrane potential}

Cells grown overnight in YPDA were diluted in fresh medium to a starting $\mathrm{OD}_{600}$ of 0.1 and grown for $24 \mathrm{~h} ; 1 \mathrm{ml}$ of the culture was harvested and washed twice with one volume of PBS buffer $(0.14 \mathrm{M} \mathrm{NaCl}, 0.0027 \mathrm{M} \mathrm{KCl}, 0.010 \mathrm{M}$ phosphate buffer $\mathrm{pH}$ 7.4). Cells were reconstituted in $5 \mathrm{ml}$ PBS to a $\mathrm{OD}_{600}$ of 0.05 . A $1 \mathrm{ml}$ aliquot was treated with $2 \mu \mathrm{M}$ tetramethylrhodamine methyl ester perchlorate (TMRE) (Molecular Probes, USA) and incubated at $37^{\circ} \mathrm{C}$ for $30 \mathrm{~min}$. As control, another aliquot of the cell suspension was treated with the same concentration of TMRE for $20 \mathrm{~min}$ followed by addition of $20 \mu \mathrm{M}$ carbonyl cyanide 3-chlorophenylhydrazone (CCCP) for $10 \mathrm{~min}$ to collapse the membrane potential. Mitochondrial mass was estimated by adding $250 \mathrm{nM}$ nonylacridine orange (NAO) (Invitrogen, USA) to a third aliquot of the cell suspension and incubated at $37^{\circ} \mathrm{C}$ for $30 \mathrm{~min}$. Both mitochondrial membrane potential and mitochondrial mass were determined by flow cytometry on a Beckman Coultier Cytomics FC500. $\triangle \Psi \mathrm{m}$ was calculated by subtracting the TMRE fluorescence of the untreated and uncoupled sample and normalized for mitochondrial mass (Miceli et al., 2012).

\section{Measurement of cellular reactive oxygen species (ROS)}

Determination of cellular ROS content was as previously described with some modifications (Gourlay and Ayscough, 2005; Yi et al., 2018). Briefly, yeast cells previously grown on solid medium were inoculated in YPDA and incubated at $30^{\circ} \mathrm{C}$ for 24 hours. Cultures were diluted in $10 \mathrm{ml}$ fresh medium to a starting $\mathrm{OD}_{600}$ of 0.1 followed by addition of $10 \mu \mathrm{g} / \mathrm{ml}$ $\mathrm{H}_{2}$ DCFDA (Invitrogen, USA) and incubation at $30^{\circ} \mathrm{C}$ for 24 hours. One $\mathrm{ml}$ of the culture was harvested, washed twice with PBS and diluted to an $\mathrm{OD}_{600}$ of 0.1 with PBS. The cell suspension was sonicated for $10 \mathrm{sec}$ with an amplitude of 20\% (QSonica Q500, USA) before analysis by flow cytometry on a Beckman Coultier Cytomics FC500. Another set of cultures without $\mathrm{H}_{2}$ DCFDA were analyzed to determine baseline fluorescence; the percentage of $\mathrm{H}_{2}$ DCFDAstained cells with higher than baseline fluorescence was used as a measure of oxidative stress ("high-ROS" cells).

\section{Western blot}

Strains were grown in YPDA medium overnight, diluted to an $\mathrm{OD}_{600}$ of 0.1 the next morning and grown until $\mathrm{OD}_{600}$ 0.5-0.6. Cells were harvested by centrifugation, cell pellets 
flash-frozen in liquid nitrogen and stored at $-80^{\circ} \mathrm{C}$. As a positive control for $\operatorname{Rad} 53$ phosphorylation, DNA damage was induced where indicated by treatment with $2 \mu \mathrm{g} / \mathrm{ml} 4$ Nitroquinoline 1-oxide (4-NQO) (Sigma) for $60 \mathrm{~min}$ before harvesting. Whole-cell protein extracts were prepared by bead-beating the pellets with $0.5 \mathrm{~mm}$ zirconia/silica beads (BioSpec) in $20 \%$ trichloroacetic acid (Scharlau) for $2 \mathrm{~min}$. Protein extracts were pelleted and resuspended in $1 \mathrm{M}$ Tris $\mathrm{pH}$ 7.6. One volume of $2 \mathrm{x}$ Laemmli buffer ( $80 \mathrm{mM}$ Tris, $8 \mathrm{mM}$ EDTA, $120 \mathrm{mM}$ DTT, $12 \%$ glycerol, $3.5 \%$ SDS) was added to the protein extracts and samples were incubated at $95^{\circ} \mathrm{C}$ for 5 min prior to loading onto a $10 \%$ polyacrylamide SDS-PAGE gel and resolving in Tris-Glycine-SDS buffer (25 mM Tris, $192 \mathrm{mM}$ glycine, 0.1\% SDS). Proteins were then transferred to a PVDF membrane (Amersham Hybond) in transfer buffer (25 mM Tris, $192 \mathrm{mM}$ glycine, $20 \%$ ethanol). The membrane was blocked in TBS-T (20 mM Tris pH 7.6, $150 \mathrm{mM}$ $\mathrm{NaCl}, 0.1 \%$ Tween-20) containing $1 \% \mathrm{BSA}$ for $1 \mathrm{~h}$ at room temperature (RT), and incubated with primary antibodies against $\operatorname{Rad} 53$ (1:4000; rabbit, ab104332, Cell Signalling) or Tubulin (1:2000; rat, YL1/2, Abcam) diluted in TBS-T containing 1\% BSA for $1 \mathrm{~h} 30 \mathrm{~min}$ at RT. After washing with TBS-T, the membrane was incubated with HRP-linked anti-rabbit (1:20 000; 31460, Thermo Scientific) or anti-rat (1:20 000; A5795, Sigma) secondary antibodies diluted in TBS-T with $1 \%$ BSA for $1 \mathrm{~h}$ at RT. After extensive washes with TBS-T, the blots were developed by chemiluminescence (ECL Bright, Agrisera) and images were taken using the ChemiDoc imaging system (Bio-Rad).

\section{Acknowledgements}

We thank Drs. Andrei Chabes (Umeå University, Umeå, Sweden), Peter Burgers (Washington University in St. Louis, MO, USA) and Akash Gunjan (Florida State University, FL, USA) for yeast strains, and Drs. Michal Jazwinski (Tulane University, LA, USA) and Anders Byström (Umeå University, Umeå, Sweden) for plasmids. We acknowledge Dr. Sushma Sharma for expert technical advice and helpful discussions, and the P. Wanrooij laboratory for critical reading of the manuscript. This project was supported by grants from the Swedish Cancer Society (19 0022JIA and 19 0098Pj 01 H), the Swedish Research Council (2019-01874), the Swedish Society for Medical Research (S17-0023), the Kempe Foundations (JCK-1830) and the Åke Wiberg Foundation (M20-0132) to P.H.W. The authors declare no competing financial interests.

\section{Author contributions}


C.M. Gorospe designed and carried out the majority of the experiments, analyzed the resulting data, supervised some activities, visualized all data and wrote parts of the manuscript. A.H. Curbelo, L. Marchhart and K. Niedźwiecka performed key experiments and analyzed the connected data. G. Carvalho conceptualized, designed and carried out some experiments, analyzed the connected data, contributed to supervision, and helped in writing the first draft. P.H. Wanrooij conceptualized the study, acquired funding, supervised the project, and wrote parts of the manuscript. All authors reviewed and edited the final version of the manuscript.

\section{References}

Al-Nahdi, A.M.T., A. John, and H. Raza. 2018. Cytoprotective effects of N-acetylcysteine on streptozotocin-induced oxidative stress and apoptosis in RIN-5F pancreatic $\beta$-cells. Cellular Physiology and Biochemistry. 51. doi:10.1159/000495200.

Appleby, R.D., W.K. Porteous, G. Hughes, A.M. James, D. Shannon, Y.H. Wei, and M.P. Murphy. 1999. Quantitation and origin of the mitochondrial membrane potential in human cells lacking mitochondrial DNA. European Journal of Biochemistry. 262. doi:10.1046/j.14321327.1999.00350.x.

Bähler, J., J.Q. Wu, M.S. Longtine, N.G. Shah, A. McKenzie, A.B. Steever, A. Wach, P. Philippsen, and J.R. Pringle. 1998. Heterologous modules for efficient and versatile PCR-based gene targeting in Schizosaccharomyces pombe. Yeast (Chichester, England). 14:943-51. doi:10.1002/(SICI)10970061(199807)14:10<943::AID-YEA292>3.0.CO;2-Y.

Beyer, T., and T. Weinert. 2014. Mec1 and Tel1: An arresting dance of resection. EMBO Journal. 33. doi:10.1002/embj.201387440.

Buchet, K., and C. Godinot. 1998. Functional F1-ATPase essential in maintaining growth and membrane potential of human mitochondrial DNA-depleted $\rho^{\circ}$ cells. Journal of Biological Chemistry. 273. doi:10.1074/jbc.273.36.22983.

Chabes, A., B. Georgieva, V. Domkin, X. Zhao, R. Rothstein, and L. Thelander. 2003. Survival of DNA damage in yeast directly depends on increased dNTP levels allowed by relaxed feedback inhibition of ribonucleotide reductase. Cell. 112:391-401.

Chung, C.-Y., K. Singh, V.N. Kotiadis, G.E. Valdebenito, J.H. Ahn, E. Topley, J. Tan, W.D. Andrews, B. Bilanges, R.D.S. Pitceathly, G. Szabadkai, M. Yuneva, and M.R. Duchen. 2021a. Constitutive activation of the PI3K-Akt-mTORC1 pathway sustains the m.3243 A> G mtDNA mutation. Nature communications. 12:6409. doi:10.1038/s41467-021-26746-2.

Chung, C.Y., G.E. Valdebenito, A.R. Chacko, and M.R. Duchen. 2021b. Rewiring cell signalling pathways in pathogenic mtDNA mutations. Trends in Cell Biology. doi:10.1016/j.tcb.2021.10.005.

Crider, D.G., L.J. Garcia-Rodriguez, P. Srivastava, L. Peraza-Reyes, K. Upadhyaya, I.R. Boldogh, and L.A. Pon. 2012. Rad53 is essential for a mitochondrial DNA inheritance checkpoint regulating $\mathrm{G} 1$ to $\mathrm{S}$ progression. J Cell Biol. 198:793-798. doi:10.1083/jcb.201205193. 
van Dijken, J.P., R.A. Weusthuis, and J.T. Pronk. 1993. Kinetics of growth and sugar consumption in yeasts. Antonie van Leeuwenhoek. 63. doi:10.1007/BF00871229.

Dirick, L., W. Bendris, V. Loubiere, T. Gostan, E. Gueydon, and E. Schwob. 2014. Metabolic and environmental conditions determine nuclear genomic instability in budding yeast lacking mitochondrial DNA. G3: Genes, Genomes, Genetics. 4:411-423. doi:10.1534/g3.113.010108.

Doherty, E., and A. Perl. 2017. Measurement of Mitochondrial Mass by Flow Cytometry during Oxidative Stress. Reactive Oxygen Species. doi:10.20455/ros.2017.839.

Ephrussi, B. 1949. Action de l'acriflavine sur les levures. I. La mutation "petite colonie." Ann Inst Pasteur. 76:351-357.

Epstein, C.B., J.A. Waddle, W. Hale, V. Davé, J. Thornton, T.L. Macatee, H.R. Garner, and R.A. Butow. 2001. Genome-wide Responses to Mitochondrial Dysfunction. Molecular Biology of the Cell. 12:297-308. doi:10.1091/mbc.12.2.297.

Francis, B.R., K.H. White, and P.E. Thorsness. 2007. Mutations in the Atp1p and Atp3p subunits of yeast ATP synthase differentially affect respiration and fermentation in Saccharomyces cerevisiae. Journal of Bioenergetics and Biomembranes. 39:127-144. doi:10.1007/s10863-0079071-4.

Gietz, R.D., R.H. Schiestl, A.R. Willems, and R.A. Woods. 1995. Studies on the transformation of intact yeast cells by the LiAc/SS-DNA/PEG procedure. Yeast (Chichester, England). 11:355-60. doi:10.1002/yea.320110408.

Giraud, M.F., and J. Velours. 1997. The absence of the mitochondrial ATP synthase $\delta$ subunit promotes a slow growth phenotype of rho- yeast cells by a lack of assembly of the catalytic sector F1. European Journal of Biochemistry. 245. doi:10.1111/j.1432-1033.1997.00813.x.

Goldring, E.S., L.I. Grossman, D. Krupnick, D.R. Cryer, and J. Marmur. 1970. The petite mutation in Yeast. Loss of mitochondrial deoxyribonucleic acid during induction of petites with ethidium bromide. Journal of Molecular Biology. 52. doi:10.1016/0022-2836(70)90033-1.

Gourlay, C.W., and K.R. Ayscough. 2005. Identification of an upstream regulatory pathway controlling actin-mediated apoptosis in yeast. Journal of Cell Science. 118. doi:10.1242/jcs.02337.

Greaves, L.C., A.K. Reeve, R.W. Taylor, and D.M. Turnbull. 2012. Mitochondrial DNA and disease. Journal of Pathology. 226. doi:10.1002/path.3028.

Gunjan, A., and A. Verreault. 2003. A Rad53 kinase-dependent surveillance mechanism that regulates histone protein levels in S. cerevisiae. Cell. 115:537-549. doi:10.1038/nrm1297.

Harrison, J.C., and J.E. Haber. 2006. Surviving the breakup: the DNA damage checkpoint. Annu Rev Genet. 40:209-235. doi:10.1146/annurev.genet.40.051206.105231.

Hoch, N.C., E.S.-W. Chen, R. Buckland, S.-C. Wang, A. Fazio, A. Hammet, A. Pellicioli, A. Chabes, M.-D. Tsai, and J. Heierhorst. 2013. Molecular basis of the essential s phase function of the rad53 checkpoint kinase. Mol Cell Biol. 33:3202-3213. doi:10.1128/MCB.00474-13.

Houten, B. van, S.E. Hunter, and J.N. Meyer. 2016. Mitochondrial DNA damage induced autophagy, cell death, and disease. Frontiers in Bioscience - Landmark. 21. doi:10.2741/4375.

Jiao, Y., S. Ma, Y. Wang, J. Li, L. Shan, Q. Liu, Y. Liu, Q. Song, F. Yu, H. Yu, H. Liu, L. Huang, and J. Chen. 2016. N-Acetyl cysteine depletes reactive oxygen species and prevents dental monomer-induced 
intrinsic mitochondrial apoptosis in vitro in human dental pulp cells. PLOS ONE. 11. doi:10.1371/journal.pone.0147858.

Jin, S.M., M. Lazarou, C. Wang, L.A. Kane, D.P. Narendra, and R.J. Youle. 2010. Mitochondrial membrane potential regulates PINK1 import and proteolytic destabilization by PARL. Journal of Cell Biology. 191. doi:10.1083/jcb.201008084.

Kenwood, B.M., J.L. Weaver, A. Bajwa, I.K. Poon, F.L. Byrne, B.A. Murrow, J.A. Calderone, L. Huang, A.S. Divakaruni, J.L. Tomsig, K. Okabe, R.H. Lo, G. Cameron Coleman, L. Columbus, Z. Yan, J.J. Saucerman, J.S. Smith, J.W. Holmes, K.R. Lynch, K.S. Ravichandran, S. Uchiyama, W.L. Santos, G.W. Rogers, M.D. Okusa, D.A. Bayliss, and K.L. Hoehn. 2014. Identification of a novel mitochondrial uncoupler that does not depolarize the plasma membrane. Molecular Metabolism. 3:114-123. doi:10.1016/j.molmet.2013.11.005.

Kirchman, P.A., S. Kim, C.Y. Lai, and S.M. Jazwinski. 1999. Interorganelle signaling is a determinant of longevity in Saccharomyces cerevisiae. Genetics. 152. doi:10.1093/genetics/152.1.179.

Kominsky, D.J., M.P. Brownson, D.L. Updike, and P.E. Thorsness. 2002. Genetic and biochemical basis for viability of yeast lacking mitochondrial genomes. Genetics. 162:1595-604. doi:10.1093/genetics/162.4.1595.

Kopinski, P.K., K.A. Janssen, P.M. Schaefer, S. Trefely, C.E. Perry, P. Potluri, J.A. Tintos-Hernandez, L.N. Singh, K.R. Karch, S.L. Campbell, M.T. Doan, H. Jiang, I. Nissim, E. Nakamaru-Ogiso, K.E. Wellen, N.W. Snyder, B.A. Garcia, and D.C. Wallace. 2019. Regulation of nuclear epigenome by mitochondrial DNA heteroplasmy. Proceedings of the National Academy of Sciences of the United States of America. 116. doi:10.1073/pnas.1906896116.

Leadsham, J.E., G. Sanders, S. Giannaki, E.L. Bastow, R. Hutton, W.R. Naeimi, M. Breitenbach, and C.W. Gourlay. 2013. Loss of Cytochrome c Oxidase Promotes RAS-Dependent ROS Production from the ER Resident NADPH Oxidase, Yno1p, in Yeast. Cell Metabolism. 18:279-286. doi:10.1016/j.cmet.2013.07.005.

Lee, O., and P.J. O'Brien. 2010. Modifications of Mitochondrial Function by Toxicants. Comprehensive Toxicology: Second Edition. 1-14. doi:10.1016/B978-0-08-046884-6.00119-6.

Lei, Y., C. Guerra Martinez, S. Torres-Odio, S.L. Bell, C.E. Birdwell, J.D. Bryant, C.W. Tong, R.O. Watson, L.C. West, and A.P. West. 2021. Elevated type I interferon responses potentiate metabolic dysfunction, inflammation, and accelerated aging in mtDNA mutator mice. Science advances. 7:eabe7548. doi:10.1126/sciadv.abe7548.

Leroy, C., C. Mann, and M.C. Marsolier. 2001. Silent repair accounts for cell cycle specificity in the signaling of oxidative DNA lesions. EMBO Journal. 20. doi:10.1093/emboj/20.11.2896.

Liao, X., and R.A. Butow. 1993. RTG1 and RTG2: two yeast genes required for a novel path of communication from mitochondria to the nucleus. Cell. 72:61-71. doi:10.1016/00928674(93)90050-z.

Liu, Z., and R.A. Butow. 2006. Mitochondrial Retrograde Signaling. Annual Review of Genetics. 40:159185. doi:10.1146/annurev.genet.40.110405.090613.

Mandal, S., P. Guptan, E. Owusu-Ansah, and U. Banerjee. 2005. Mitochondrial regulation of cell cycle progression during development as revealed by the tenured mutation in Drosophila.

Developmental cell. 9:843-54. doi:10.1016/j.devcel.2005.11.006. 
Meeusen, S.L., and J. Nunnari. 2005. How mitochondria fuse. Current opinion in cell biology. 17:38994. doi:10.1016/j.ceb.2005.06.014.

Miceli, M. v, J.C. Jiang, A. Tiwari, J.F. Rodriguez-Quiñones, and S.M. Jazwinski. 2012. Loss of mitochondrial membrane potential triggers the retrograde response extending yeast replicative lifespan. Frontiers in genetics. 2:102. doi:10.3389/fgene.2011.00102.

Mitra, K., C. Wunder, B. Roysam, G. Lin, and J. Lippincott-Schwartz. 2009. A hyperfused mitochondrial state achieved at G1-S regulates cyclin E buildup and entry into S phase. Proceedings of the National Academy of Sciences. 106:11960-11965. doi:10.1073/pnas.0904875106.

Mottis, A., S. Herzig, and J. Auwerx. 2019. Mitocellular communication: Shaping health and disease. Science (New York, N.Y.). 366:827-832. doi:10.1126/science.aax3768.

Navadgi Patil, V.M., and P.M. Burgers. 2011. Cell-cycle-specific activators of the Mec1/ATR checkpoint kinase. Biochemical Society Transactions. 39:600-605. doi:10.1042/BST0390600.

Nunnari, J., and A. Suomalainen. 2012. Mitochondria: in sickness and in health. Cell. 148:1145-1159. doi:10.1016/j.cell.2012.02.035.

Owusu-Ansah, E., A. Yavari, S. Mandal, and U. Banerjee. 2008. Distinct mitochondrial retrograde signals control the G1-S cell cycle checkpoint. Nature Genetics. 40:356-361. doi:10.1038/ng.2007.50.

Parikh, V.S., M.M. Morgan, R. Scott, L.S. Clements, and R.A. Butow. 1987. The mitochondrial genotype can influence nuclear gene expression in yeast. Science. 235. doi:10.1126/science.3027892.

Raimundo, N. 2014. Mitochondrial pathology: stress signals from the energy factory. Trends in molecular medicine. 20:282-292. doi:10.1016/j.molmed.2014.01.005.

Rothermel, B.A., J.L. Thornton, and R.A. Butow. 1997. Rtg3p, a basic helix-loop-helix/leucine zipper protein that functions in mitochondrial-induced changes in gene expression, contains independent activation domains. The Journal of biological chemistry. 272:19801-7. doi:10.1074/jbc.272.32.19801.

Sanchez, Y., B.A. Desany, W.J. Jones, Q. Liu, B. Wang, and S.J. Elledge. 1996. Regulation of RAD53 by the ATM-like kinases MEC1 and TEL1 in yeast cell cycle checkpoint pathways. Science. 271:357360.

Schieke, S.M., J.P. McCoy Jr., and T. Finkel. 2008. Coordination of mitochondrial bioenergetics with G1 phase cell cycle progression. Cell Cycle. 7:1782-1787. doi:10.4161/cc.7.12.6067.

Tsaponina, O., E. Barsoum, S.U. Aström, and A. Chabes. 2011. Ixr1 is required for the expression of the ribonucleotide reductase Rnr1 and maintenance of dNTP pools. PLoS genetics. 7:e1002061. doi:10.1371/journal.pgen.1002061.

Veatch, J.R., M.A. McMurray, Z.W. Nelson, and D.E. Gottschling. 2009. Mitochondrial Dysfunction Leads to Nuclear Genome Instability via an Iron-Sulfur Cluster Defect. Cell. 137:1247-1258. doi:10.1016/j.cell.2009.04.014.

Wanrooij, P.H., M.K.M. Engqvist, J.M.E. Forslund, C. Navarrete, A.K. Nilsson, J. Sedman, S. Wanrooij, A.R. Clausen, and A. Chabes. 2017. Ribonucleotides incorporated by the yeast mitochondrial DNA polymerase are not repaired. Proceedings of the National Academy of Sciences of the United States of America. 114. doi:10.1073/pnas.1713085114. 
bioRxiv preprint doi: https://doi.org/10.1101/2022.02.18.480979; this version posted February $18,2022$. The copyright holder for this

preprint (which was not certified by peer review) is the author/funder, who has granted bioRxiv a license to display the preprint in perpetuity. It is made available under aCC-BY 4.0 International license.

Wanrooij, P.H., E. Tannous, S. Kumar, V.M. Navadgi-Patil, and P.M. Burgers. 2016. Probing the Mec1ATR Checkpoint Activation Mechanism with Small Peptides. Journal of Biological Chemistry. 291:393-401. doi:10.1074/jbc.M115.687145.

Weinberger, M., L. Feng, A. Paul, D.L. Smith, R.D. Hontz, J.S. Smith, M. Vujcic, K.K. Singh, J.A. Huberman, and W.C. Burhans. 2007. DNA replication stress is a determinant of chronological lifespan in budding yeast. PLoS One. 2:e748. doi:10.1371/journal.pone.0000748.

Yi, D.G., S. Hong, and W.K. Huh. 2018. Mitochondrial dysfunction reduces yeast replicative lifespan by elevating RAS-dependent ROS production by the ER-localized NADPH oxidase Yno1. PLOS ONE. 13. doi:10.1371/journal.pone.0198619.

Zhao, X., E.G. Muller, and R. Rothstein. 1998. A suppressor of two essential checkpoint genes identifies a novel protein that negatively affects dNTP pools. Molecular cell. 2:329-40. doi:10.1016/s1097-2765(00)80277-4.

Zyrina, A.N., M.I. Sorokin, S.S. Sokolov, D.A. Knorre, and F.F. Severin. 2015. Mitochondrial retrograde signaling inhibits the survival during prolong S/G2 arrest in Saccharomyces cerevisiae. Oncotarget. 6:44084-44094. doi:10.18632/oncotarget.6406. 


\section{Figure legends}

Fig. 1. Loss of mtDNA induces a delay in transition from $G 1$ to $S$ phase of the cell cycle. (A) Growth of wild-type (WT; AC403) $\rho^{+}$and $\rho^{0}$ cells in YPDA solid medium imaged after 48 $\mathrm{h}$ (left panel), and colony area measured relative to WT $\rho^{+}$(right panel). (B) Representative DNA histogram of unsynchronized WT (AC402) $\rho^{+}$and $\rho^{0}$ cells grown to early logarithmic phase in YPDA. $1 C$ and $2 C$ indicate populations with single and double chromosome content, corresponding to cells in G1 and G2, respectively. The cell cycle profile was analyzed using the multicycle model in FCS Express to determine the percentage of cells in G1 (red), S (orange) and G2 (blue) phase. (C) Quantification of the percentage of cells in G1, S or G2 phase. Values represent the average of at least 4 independent experiments including the one in Fig. 1B, and error bars indicate standard deviation. The two-tailed Student's t-test was performed to determine statistical significance between the G1 populations in WT $\rho^{+}$and $\rho^{0}$ cultures. ${ }^{* * * * p}$ $<0.0001$. (D) DNA histogram of WT (AC402) $\rho^{+}$and $\rho^{0}$ cells released from G1 synchrony achieved by treatment with $10 \mu \mathrm{g} / \mathrm{ml} \alpha$-factor. Cells were sampled every 10 minutes after release. The experiment was repeated at least three times; a representative experiment is shown. (E) Quantification of the percentage of G1 (solid lines) and S phase (dashed lines) cells after release from G1 synchrony in the experiment shown in Fig. 1D. (F) Quantification of the percentage of G1 (solid lines) and S phase (dashed lines) cells after release of WT $\rho^{+}$and $\rho^{0}$ cells from G2 synchrony achieved by nocodazole treatment. The DNA histograms are shown in Fig. S1B. Values represent data from a single experiment. See also Fig. S1.

Fig. 2. The Tel1, Mec1 and Rad53 checkpoint kinases are redundant for the G1-S delay in $\boldsymbol{\rho}^{0}$ cells. (A-B) Quantification of the cell cycle profiles of WT, tell $\Delta, \operatorname{sml} 1 \Delta$, mec $1 \Delta \operatorname{sml} 1 \Delta$ and $\operatorname{rad} 53 \Delta \operatorname{sml} 1 \Delta \rho^{+}$and $\rho^{0}$ cells. Values represent the average of at least 3 independent experiments and error bars indicate standard deviation. The G1 population in each $\rho^{+}$and its $\rho^{0}$ variant was compared using the two-tailed Student's t-test. $* * * * p<0.0001, * * * \mathrm{p}<0.001$. The same WT data is presented in both panels. Representative DNA histograms are shown in Fig. S2A. (C) Western blot analysis of Rad53 and $\alpha$-Tubulin in WT $\rho^{+}$and $\rho^{0}$ cells harvested in early log phase. WT $\rho^{+}$ cells treated with 4-NQO for $60 \mathrm{~min}$ before harvesting served as a positive control for phosphorylation and the consequent shift in migration of Rad53p. $\operatorname{rad} 53 \Delta \operatorname{sml} 1 \Delta \rho^{+}$cells served as the negative control. See also Fig. S2. 
Fig. 3. The G1-S transition delay in $\rho^{0}$ cells does not require the RTG retrograde pathway. Quantification of the cell cycle profiles of WT, $\operatorname{rtg} 2 \Delta$ and $r \operatorname{tg} 3 \Delta \rho^{+}$and $\rho^{0}$ cells. Values represent the average of at least 4 independent experiments, and error bars indicate standard deviation. The G1 population in each $\rho^{+}$and its $\rho^{0}$ variant was compared using the two-tailed Student's ttest. $* * * \mathrm{p}<0.0001, * * \mathrm{p}<0.01$. Representative DNA histograms are shown in Fig. S3.

Fig. 4. The loss of $\Delta \Psi \mathrm{m}$, but not the inhibition of mitochondrial ATP synthesis, delays G1to-S progression in WT $\boldsymbol{\rho}^{+}$cells. (A) The percentage of G1 cells in WT $\rho^{+}$and $\rho^{0}$ cells left untreated or treated with $20 \mu \mathrm{M}$ of oligomycin to inhibit mitochondrial ATP synthesis. Aliquots were harvested upon addition of the drug $(0 \mathrm{~min})$ and every $15 \mathrm{~min}$ thereafter. Values represent the average of two independent experiments, and error bars indicate standard deviation. Representative DNA histograms and the quantification of S phase cells are shown in Fig. S4AB. (B) The percentage of G1 (solid lines) and S phase (dashed lines) cells in cultures of WT $\rho^{+}$ cells left untreated or treated with $30 \mu \mathrm{M}$ of BAM15. Aliquots were harvested upon addition of the drug $(0 \mathrm{~min})$ and every $15 \mathrm{~min}$ thereafter. Representative DNA histograms are shown in Fig. S4C. Values represent data from a single experiment repeated at least three times. (C) DNA histogram of WT $\rho^{+}$cells synchronized in G1 with $10 \mu \mathrm{g} / \mathrm{ml} \alpha$-factor and released into media with or without $30 \mu \mathrm{M}$ BAM15. Cells were sampled upon release (time 0 ) and every 10 minutes thereafter. (D) Quantification of G1 (solid lines) and S phase (dashed lines) cells in the experiment presented in panel C. Values represent data from a single experiment. See also Fig. S4.

Fig. 5. Uncoupler treatment exacerbates the cell cycle phenotype of $\boldsymbol{\rho}^{0}$ cells. (A) $\Delta \Psi \mathrm{m}$ normalized to mitochondrial mass was measured in WT (AC403) $\rho^{+}$and $\rho^{0}$ cells as described in Materials and Methods. The average of seven independent experiments is shown; error bars represent standard deviation. The groups were compared using one-way ANOVA; ****p $<0.0001$. The same data is shown in Fig. 6A. (B) The percentage of G1 (solid lines) and S phase (dashed lines) cells in cultures of WT $\rho^{0}$ cells left untreated or treated with $30 \mu \mathrm{M}$ of BAM15. Aliquots were harvested upon addition of the drug $(0 \mathrm{~min})$ and every $15 \mathrm{~min}$ thereafter. Values represent data from a single experiment repeated at least three times. Representative DNA histograms are shown in Fig. S5A. (C) DNA histograms of WT (AC402) $\rho^{0}$ cells synchronized in G1 with $10 \mu \mathrm{g} / \mathrm{ml} \alpha$-factor and released into media with or without $30 \mu \mathrm{M}$ BAM15. Aliquots 
were sampled upon release (time 0) and every 10 minutes thereafter. (D) Quantification of G1 (solid lines) and S phase (dashed lines) cells in the experiment presented in Fig. 5C (untreated and BAM15-treated $\rho^{0}$ cells); the $\rho^{+}$control data is from Fig. 4C. Representative data from a single experiment is shown. See also Fig. S5.

Fig. 6. The cell cycle delay can be rescued by increasing the $\Delta \Psi \mathrm{m}$ of $\rho^{0}$ cells. (A) $\Delta \Psi \mathrm{m}$ normalized to mitochondrial mass was measured in WT (AC403), ATP1-111 and cox4 $\rho^{+}$and $\rho^{0}$ cells as described in Materials and Methods. Histograms of TMRE and NAO fluorescence are presented in Fig. S6A-B. The average of seven independent experiments is shown; error bars represent standard deviation. The groups were compared by one-way ANOVA. ****p $<0.0001$, ${ }^{* *} \mathrm{p}<0.01,{ }^{*} \mathrm{p}<0.05, \mathrm{~ns} \mathrm{p}>0.05$ compared to respective $\rho^{+}$; \#\#\# $<0.0001, \# \mathrm{p}<0.01$ compared to indicated strain. WT $\rho^{0}$ did not significantly differ from $\operatorname{cox} 4 \Delta \rho^{0} ; \mathrm{WT} \rho^{+} v s$. $\operatorname{cox} 4 \Delta \rho^{0}$ : \#\#\#\#; WT $\rho^{0}$ vs. ATP1-111 $\rho^{+}$: \#\#. (B) Representative DNA histograms of WT (AC403), ATP1-111 and $\operatorname{cox} 4 \Delta \rho^{+}$and $\rho^{0}$ cells grown to early-logarithmic phase in YPDA. (C) Quantification of the percentage of cells in G1, S or G2 phase in panel B. Values represent the average of at least 3 independent experiments, and error bars indicate standard deviation. The two-tailed Student's ttest was performed to determine statistical significance between the G1 populations of each strains $\rho^{+}$and $\rho^{0}$ variants. ${ }^{*} \mathrm{p}<0.01$, ns $\mathrm{p}>0.05$. (D) Quantification of the colony sizes of WT (AC403), ATP 1-111 and $\operatorname{cox} 4 \Delta \rho^{+}$and $\rho^{0}$ cells grown on the same YPDA plate for $48 \mathrm{~h}$ as shown in Fig. S6C; the average area of WT $\rho^{+}$colonies was set to 1 . The groups were compared by oneway ANOVA. **** $\mathrm{p}<0.0001$, ns $\mathrm{p}>0.05$ compared to the respective $\rho^{+} ; \# \# \# \# \mathrm{p}<0.0001$ compared to the indicated strain. (E-F) The percentage of WT (AC403), ATP1-111 and cox4A $\rho^{+}(\mathbf{E})$ and $\rho^{0}$ cells $(\mathbf{F})$ in G1 phase in untreated cultures (solid lines) or after treament with 20 $\mu \mathrm{M}$ of BAM15 (dashed lines). The average of three independent experiments is shown; error bars represent standard deviation. Percentage of cells in G1 phase between WT and $\operatorname{cox} 4 \Delta \rho^{+}$ cells at specific time points was compared by two-tailed Student's t-test. ${ }^{* *} \mathrm{p}<0.001,{ }^{*} \mathrm{p}<0.05$, ns $\mathrm{p}>0.05$. See also Fig. S6.

Fig. 7. Levels of oxidative stress do not correlate with the extent of the G1-to-S delay. (A) A representative DNA histogram of WT (AC402) $\rho^{+}$cells grown until early logarithmic stage and treated with $400 \mu \mathrm{M} \mathrm{H}_{2} \mathrm{O}_{2}$ for 60 mins. Additional timepoints are shown in Fig. S7A. (B) Quantification of G1 (solid lines) and S phase (dashed lines) cells in the experiment presented 
in Fig. 7A. (C) Quantification of \% of G1 (solid lines) and S phase (dashed lines) cells in WT $\rho^{+}$(upper panel) and WT $\rho^{0}$ (lower panel) strains treated with $30 \mathrm{mM}$ NAC or $20 \mathrm{mM} \mathrm{GSH}$ for $2 \mathrm{~h}$. DNA histograms are shown in Fig. S7B. (D) Quantification of the TMRE uptake of WT $\rho^{+}$ cells treated with $30 \mathrm{mM}$ NAC, $10 \mathrm{mM}$ GSH or $30 \mu \mathrm{M}$ CCCP. Relative TMRE uptake was calculated using the geometric mean of the flourescence intensities of 20,000 cells, and the value of the untreated control was set to 100 . The average of four independent experiments is shown; error bars represent standard deviation. The control and the treated samples were compared by one-way ANOVA. $* * * * p<0.0001$. A histogram from a representative experiment is shown in Fig. S7C. (E) Quantification of the percentage of cells with high levels of oxidative stress as measured by the fluorescence intensity of $\mathrm{H}_{2}$ DCFDA. The average of $\geq 8$ independent experiments is shown; error bars represent standard deviation. Comparison between variants and strains was performed by one-way ANOVA. $* * * * p<0.0001,{ }^{*} \mathrm{p}<0.05$, ns $\mathrm{p}>0.05$ compared to the corresponding $\rho^{+}$; \#\#\#\#p<0.0001 or ns $\mathrm{p}>0.05$ compared to the indicated strain. A representative experiment is shown in Fig. S7D. See also Fig. S7. 
Table 1. Yeast strains used in this study

\begin{tabular}{|c|c|c|}
\hline STRAIN & GENOTYPE & SOURCE \\
\hline AC402 & 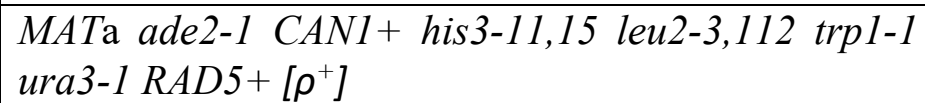 & (Chabes et al., 2003) \\
\hline $\mathrm{AC} 403$ & MATa & $\begin{array}{l}\text { (Wanrooij et al., } \\
\text { 2017) }\end{array}$ \\
\hline $\mathrm{AC} 402 \rho^{0}$ & $\operatorname{MATa}\left[\rho^{0}\right]$ & This study \\
\hline $\mathrm{AC} 403 \rho^{0}$ & $M A T \alpha\left[\rho^{0}\right]$ & This study \\
\hline AKE628 & MATa tell $\triangle:$ HIS3 $\left[\rho^{+}\right]$ & A. Chabes ${ }^{\mathrm{a}}$ \\
\hline AKE628 $\rho^{0}$ & MATa tell $\triangle:: H I S 3\left[\rho^{0}\right]$ & This study \\
\hline TOY711 & MATa sml1A::HIS3 mec1A::TRP1 $\left[\rho^{+}\right]$ & $\begin{array}{l}\text { (Tsaponina et al., } \\
\text { 2011) }\end{array}$ \\
\hline TOY711 $\rho^{0}$ & MATа sml1A::HIS3 mec $1 \Delta: \because$ TRP1 $\left[\rho^{0}\right]$ & This study \\
\hline TOY722 & MATa $\operatorname{sml} 1 \Delta:: H I S 3\left[\rho^{+}\right]$ & A. Chabes ${ }^{\mathrm{a}}$ \\
\hline TOY722 $\rho^{0}$ & MATa $\operatorname{smll\Delta } \because: H I S 3\left[\rho^{0}\right]$ & This study \\
\hline PW36-3B & MATa sml1A::HIS rad53A $\because H Y G\left[\rho^{+}\right]$ & This study \\
\hline PW36-3B $\rho^{0}$ & MATa sml1A: $\because H I S$ rad534 $\because H Y G\left[\rho^{0}\right]$ & This study \\
\hline PW38-5B & 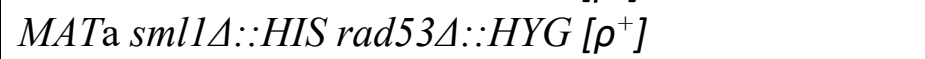 & This study \\
\hline PW38-5B $\rho^{0}$ & MATa $\operatorname{sml} 1 \Delta \because: H I S$ rad53A $\because H Y G\left[\rho^{0}\right]$ & This study \\
\hline PW39-3B & 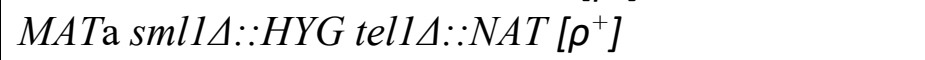 & This study \\
\hline PW39-3B $\rho^{0}$ & MATa sml1A::HYG tell $\triangle \because: N A T\left[\rho^{0}\right]$ & This study \\
\hline PW64-A & MATa $\operatorname{rtg} 2 \Delta:: K a n M X 4\left[\rho^{+}\right]$ & This study \\
\hline PW64-A $\rho^{0}$ & MATa $\operatorname{rtg} 2 \Delta \because K a n M X 4\left[\rho^{0}\right]$ & This study \\
\hline PW65-D & MATa $\operatorname{rtg} 3 \triangle: \because K a n M X 4\left[\rho^{+}\right]$ & This study \\
\hline PW65-D $\rho^{0}$ & MATa $\operatorname{rtg} 3 \triangle \because: \operatorname{KanMX} 4\left[\rho^{0}\right]$ & This study \\
\hline PW66-1C & MAT $\alpha \operatorname{cox} 4 \Delta \because N a t M X\left[\rho^{+}\right]$ & This study \\
\hline PW66-1C $\rho^{0}$ & $M A T \alpha \operatorname{cox} 4 \Delta: N$ NatMX $\left[\rho^{0}\right]$ & This study \\
\hline PW72 & $M A T \alpha A T P 1-111\left[\rho^{+}\right]$ & This study \\
\hline PW72 $\rho^{0}$ & $M A T \alpha A T P 1-111\left[\rho^{0}\right]$ & This study \\
\hline U960-5C & MATa ho ade2-1 trp1-1 can1-100 leu2-3,112 his3- & (Gunjan \\
\hline & 11,15 ura3-1 rad53::HIS3 sml1-1 RAD5+ $\left[\rho^{+}\right]$ & $\begin{array}{l}\text { Verreault, 2003; } \\
\text { Zhao et al., 1998) }\end{array}$ \\
\hline $\mathrm{U} 960-5 \mathrm{C} \rho^{0}$ & MATа U960-5C $\left[\rho^{0}\right]$ & This study \\
\hline
\end{tabular}

All strains are isogenic to W303. With the exception of U960-5c, all strains are derivatives of W4069-4c (AC402); only genotypes differing from AC402 are listed.

aUmeå University, Umeå, Sweden 
bioRxiv preprint doi: https://doi.org/10.1101/2022.02.18.480979; this version posted February 18, 2022. The copyright holder for this

preprint (which was not certified by peer review) is the author/funder, who has granted bioRxiv a license to display the preprint in perpetuity. It is made available under aCC-BY 4.0 International license.

Table 2. Oligonucleotides used in the study

\begin{tabular}{l|l} 
NAME & SEQUENCE \\
\hline Actin (forward) & 5'-CAT GAT ACC TTG GTG TCT TGG-3' \\
Actin (reverse) & 5'-GTA TGT GTA AAG CCG GTT TTG-3' \\
Cox1 (forward) & 5'-CTA CAG ATA CAG CAT TTC CAA GA-3' \\
Cox1 (reverse) & 5'-GTG CCT GAA TAG ATG ATA ATG GT-3'
\end{tabular}


A
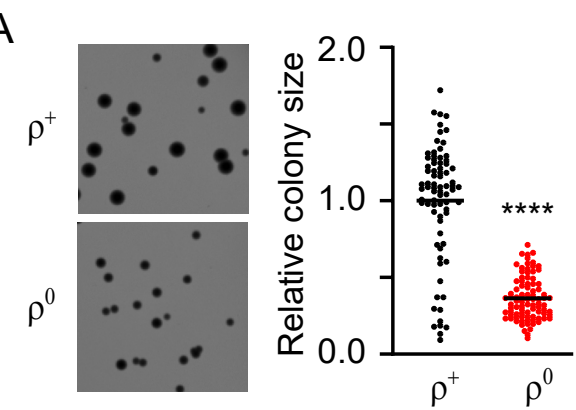

B

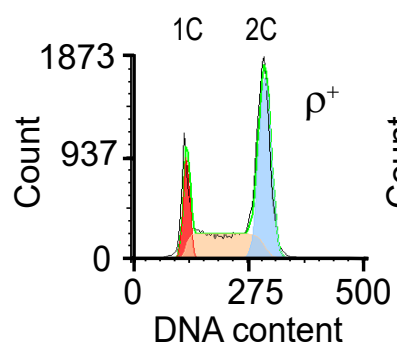

$\mathrm{C}$

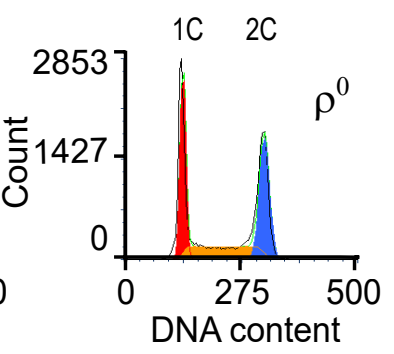

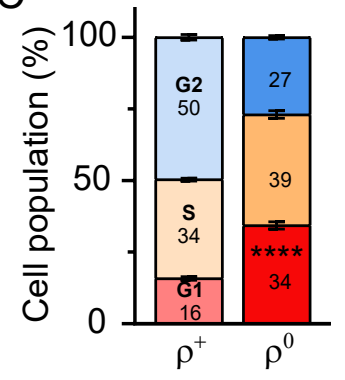

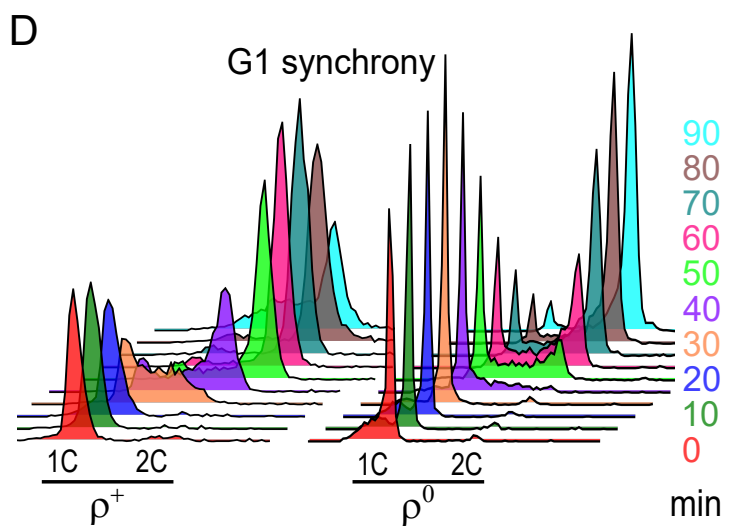

$\mathrm{E}$

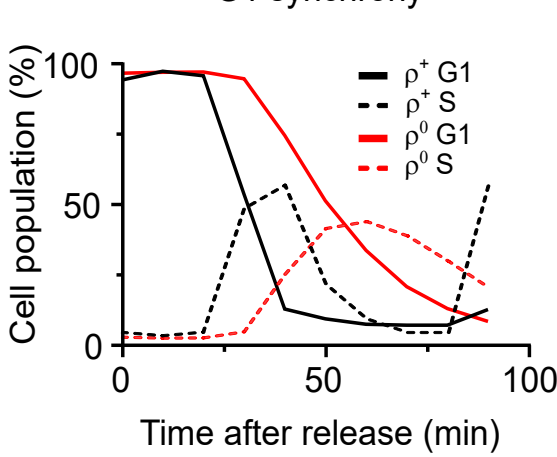

$\mathrm{F}$

G2 synchrony

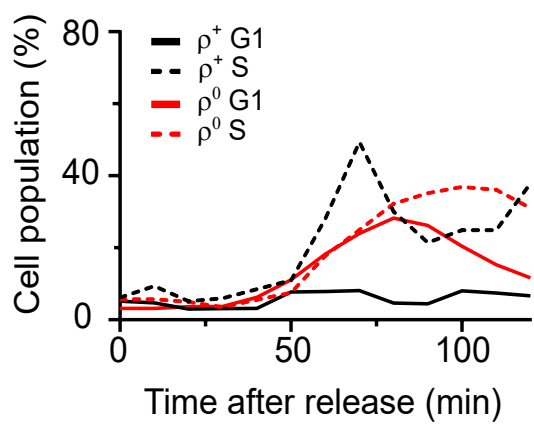

Fig 1 
A

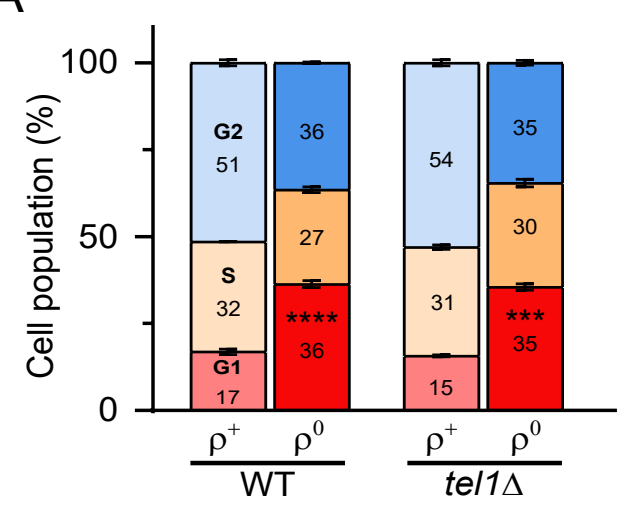

C

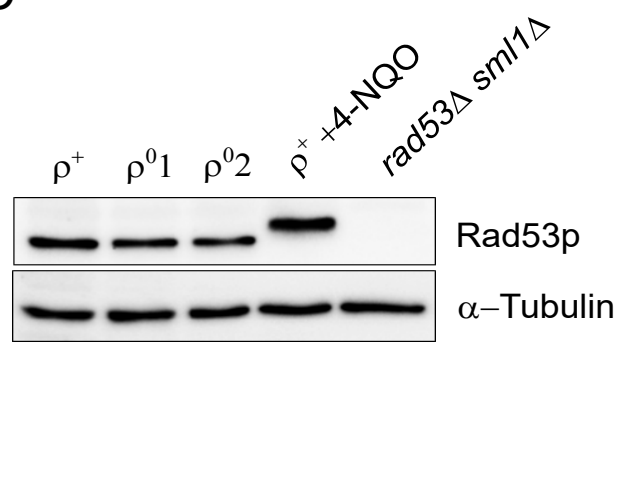

B

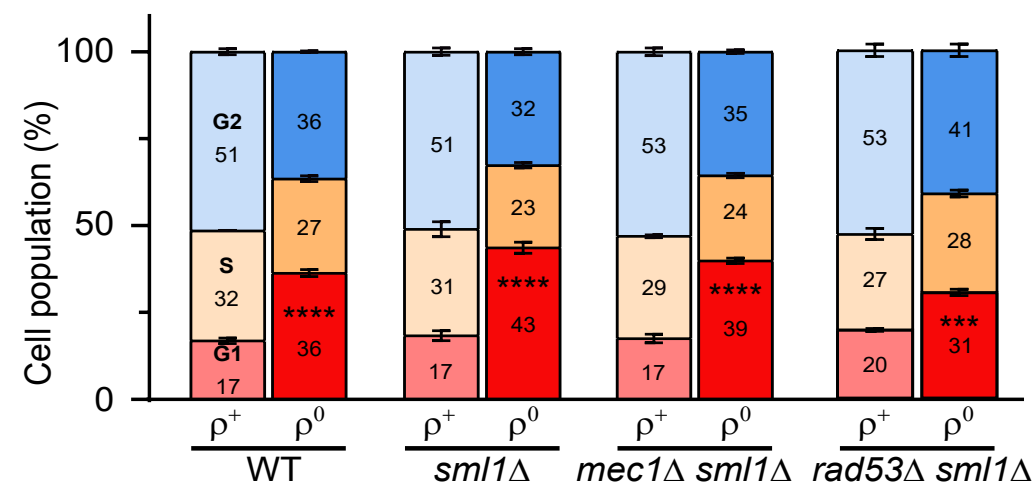

Fig 2 


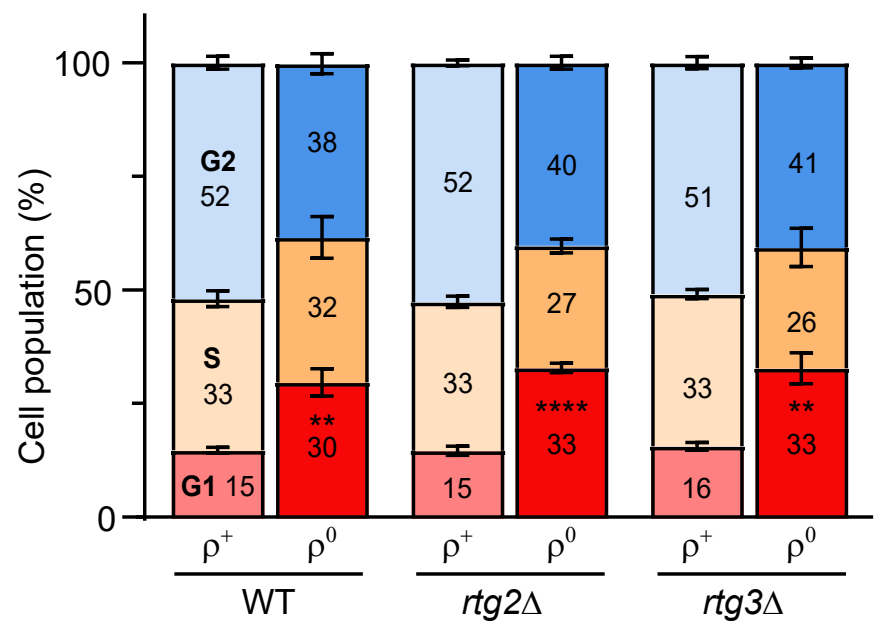

Fig 3 
A

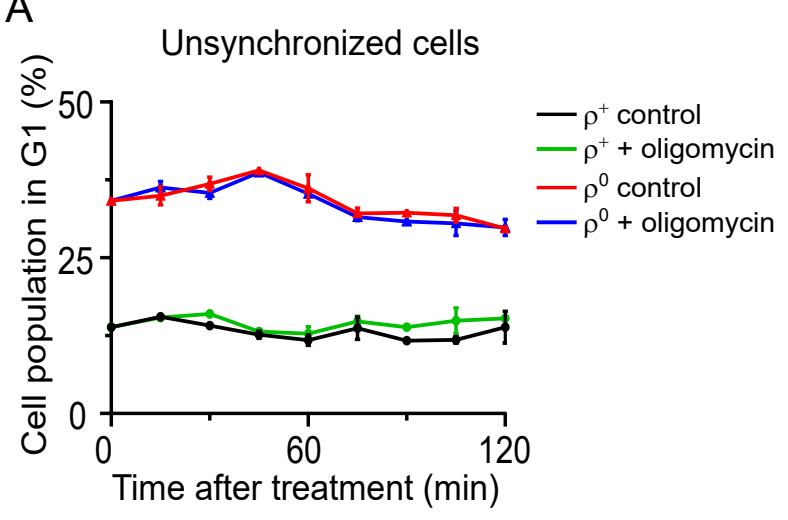

C

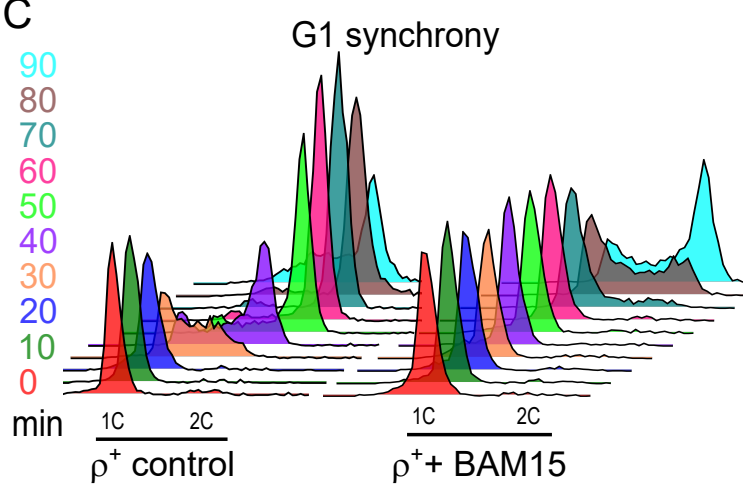

B

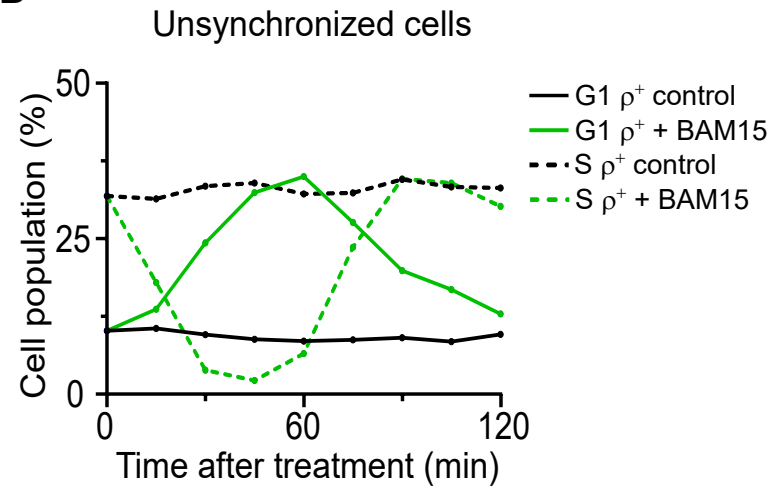

D

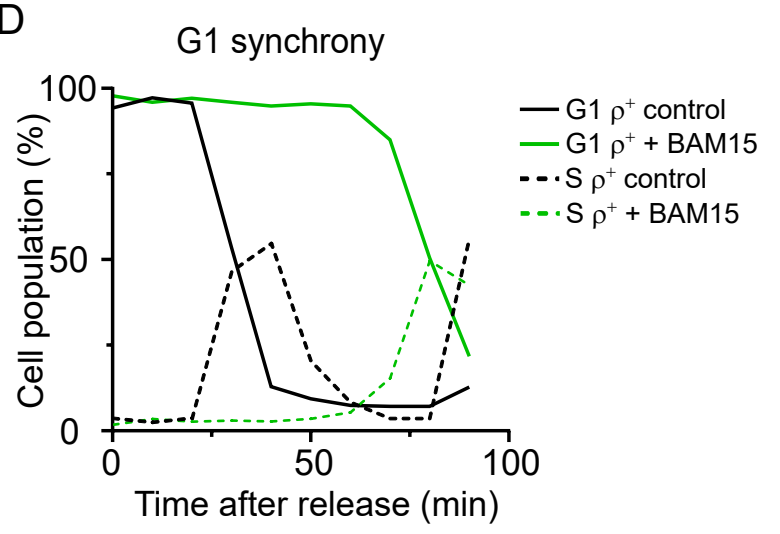

Fig 4 
A

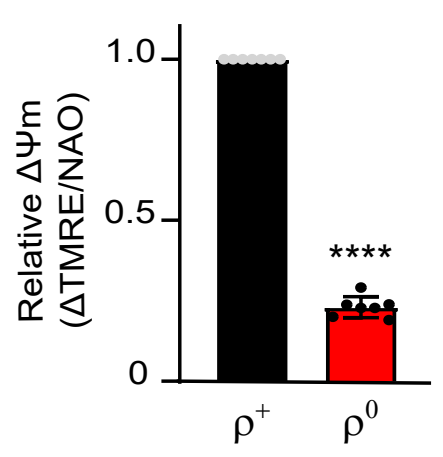

C

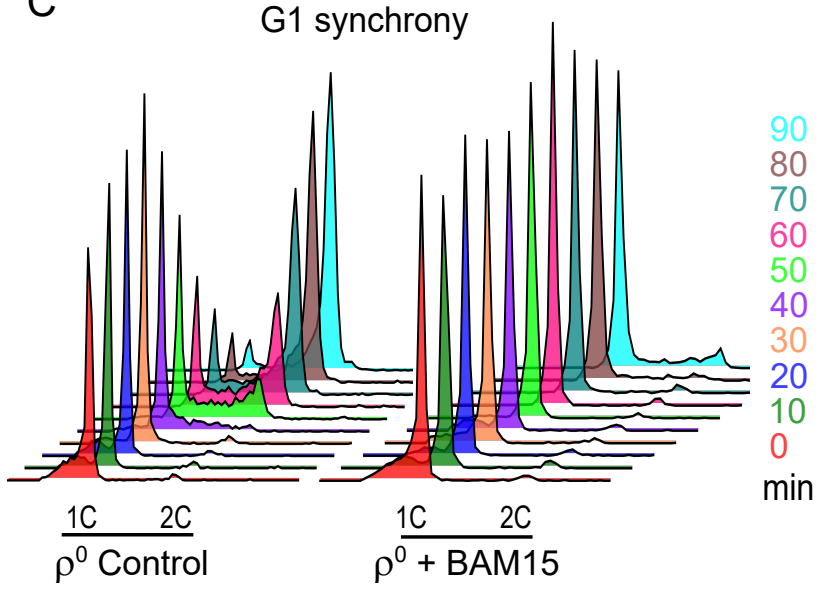

D

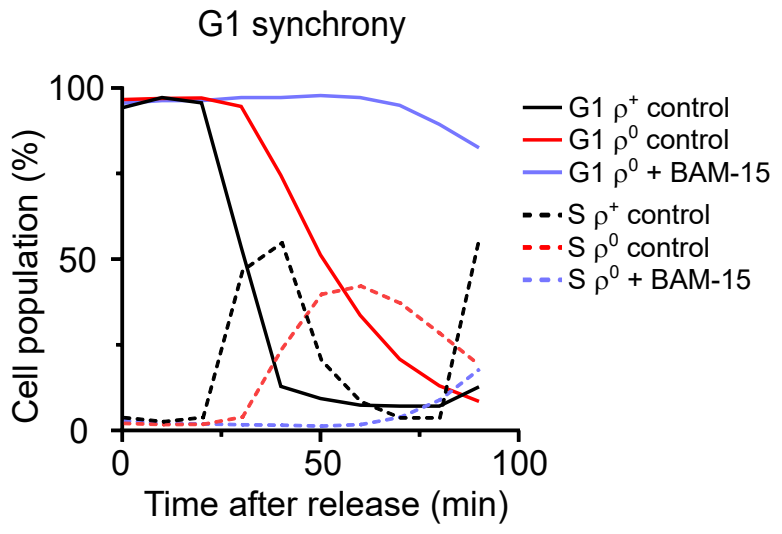

Fig 5 
A
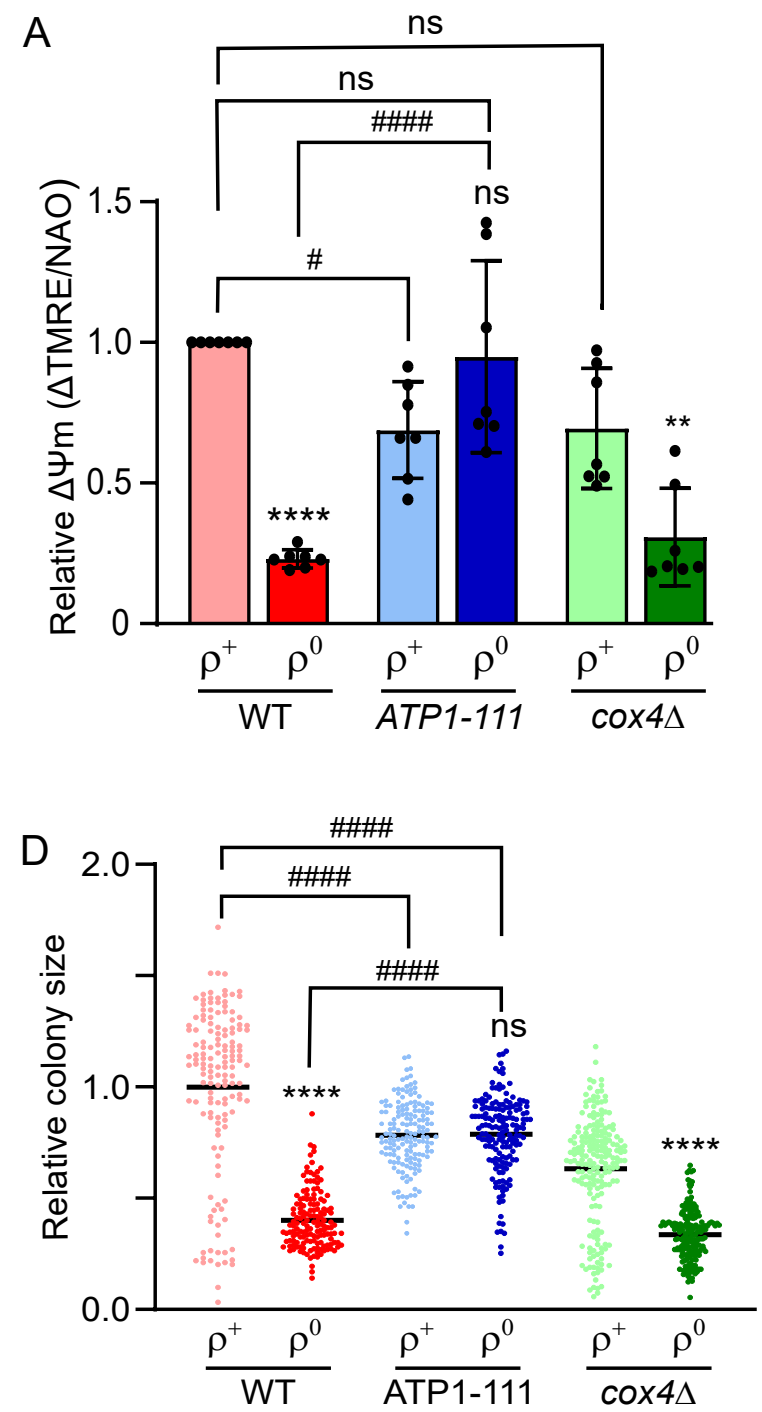

B

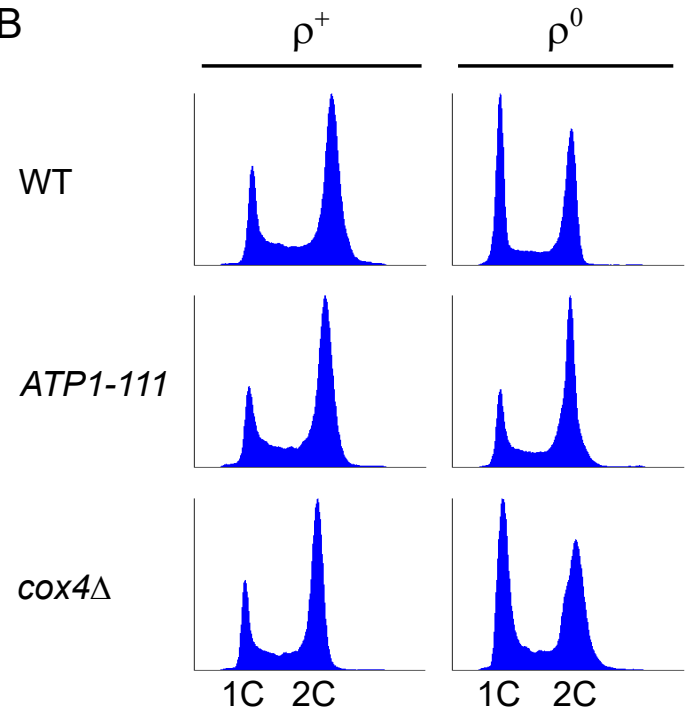

C

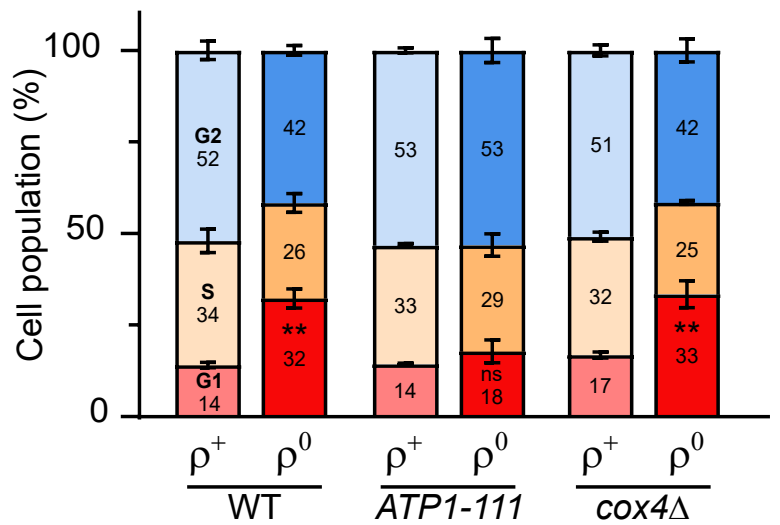

E
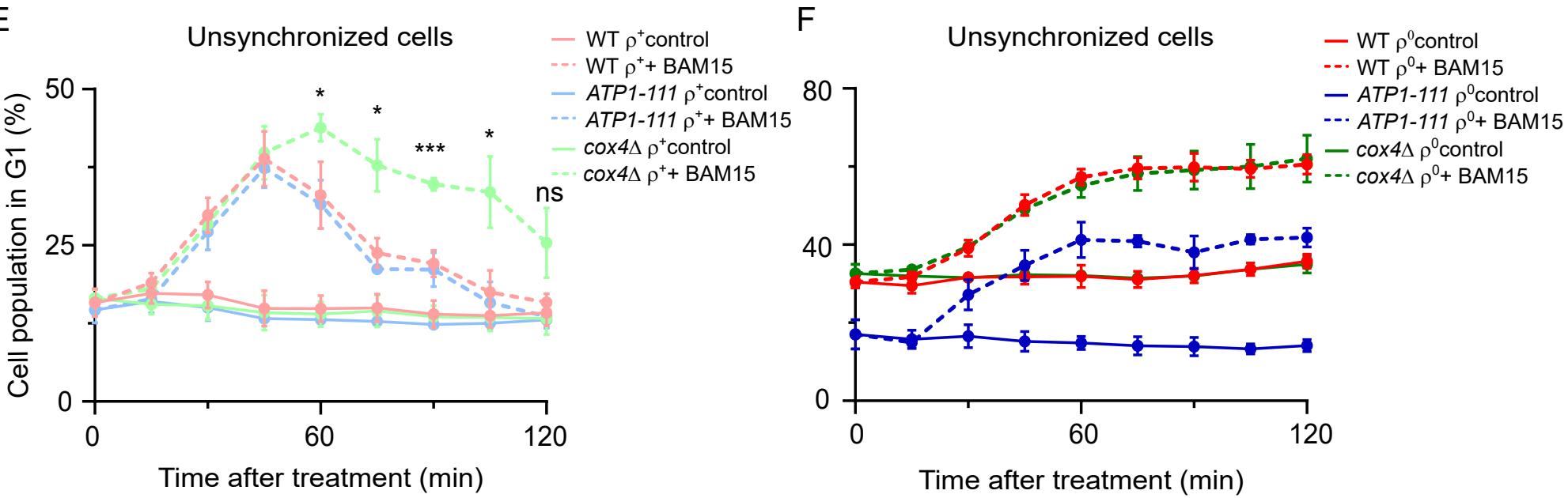

Fig 6 
A
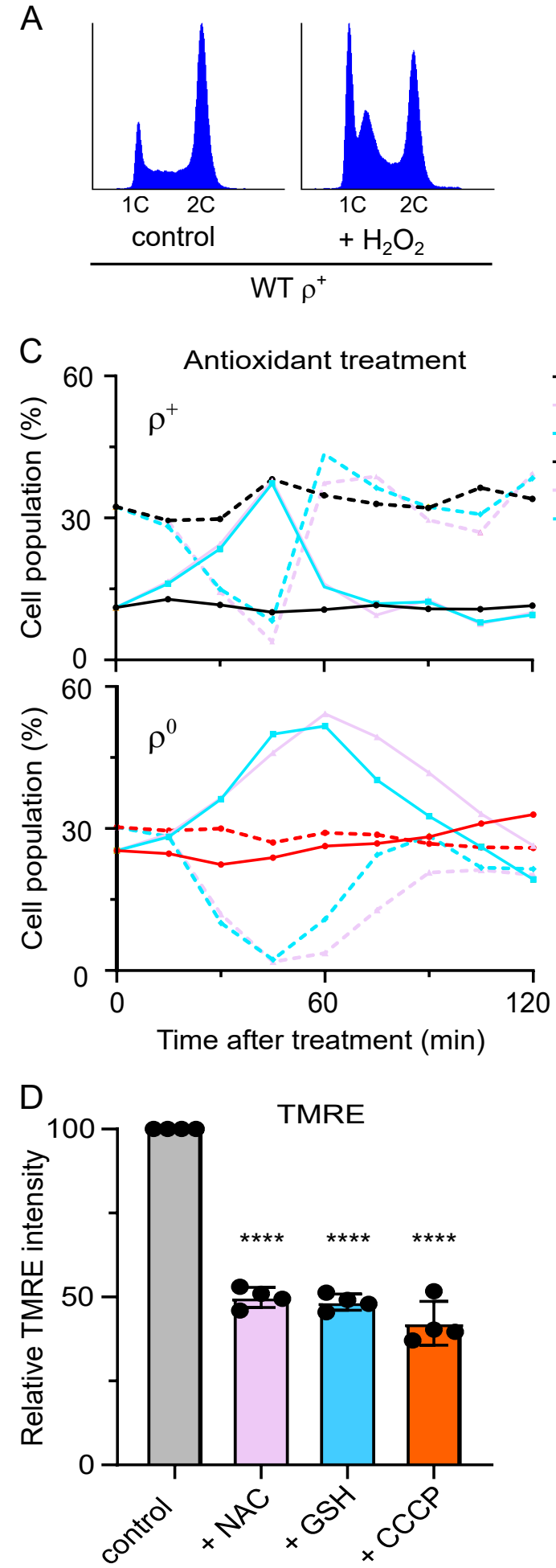

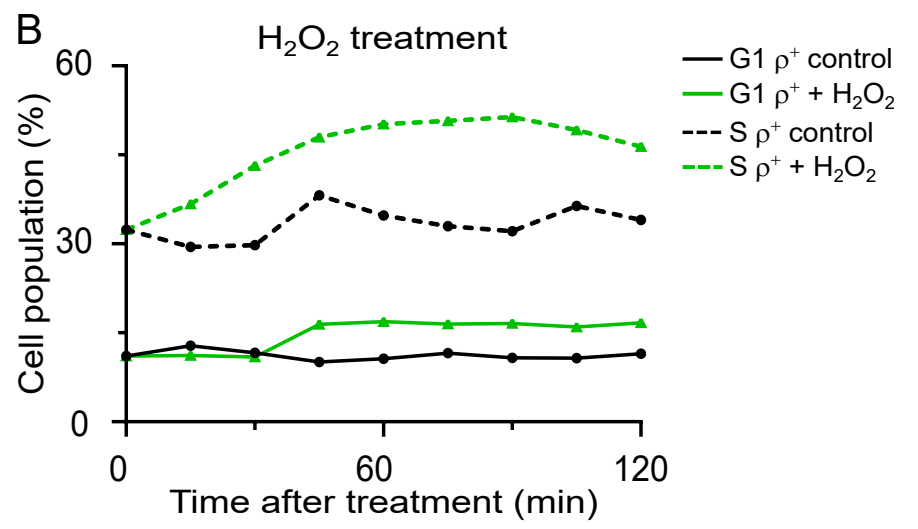

E

Oxidative stress

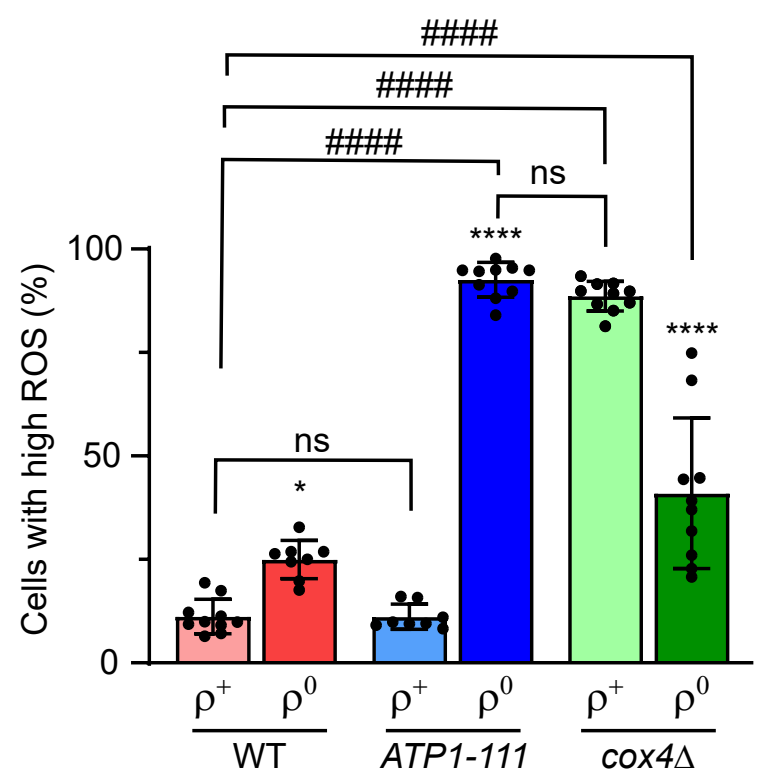

